\title{
Weather Shocks and Migration Intentions in Western Africa: Insights from a Multilevel Analysis*
}

Simone Bertolia, Frédéric Docquier, Hillel Rapoport \& Ilse Ruyssen ${ }^{\dagger}$

\section{Highlights}

- This paper characterizes the relationship between weather shocks and (internal and international) migration intentions through the combination of individual survey data on migration intentions with measures of localized weather shocks for Western African countries over 2008-2016.

I It finds that droughts are associated with a higher probability of domestic migration intentions in Senegal, Niger and Ivory Coast.

- The effect on international migration intentions are only significant in Niger. They are amplified, but qualitatively similar, when restricting the sample to rural low-skilled respondents.

\footnotetext{
* The authors are grateful to the Agence Fran, caise de D'eveloppement for financial support (convention IRS/ECO/437-2017). The paper benefited from helpful comments from Ilan Noy and from participants at the $12^{\text {th }}$ AFD-World Bank Migration and Development Conference, the CeMig Lecture Series "Root Causes of Forced Migration: Interdisciplinary Insights and Political Challenges", and the $8^{\text {th }}$ Meeting on International Economics at the University Jaume I. We also thank Olivier Santoni and Stefanija Veljanoska for providing excellent research assistance. F. Docquier acknowledges financial support from the ARC convention on "New approaches to understanding and modelling global migration trends" (convention 18/23-091). S. Bertoli acknowledges the support from the Agence Nationale de la Recherche through the program "Investissements d'avenir" (ANR-10-LABX-14-01) H. Rapoport acknowledges support from Agence Nationale de la Recherche under the framework of the Investissements d'avenir program (ANR-17-EURE-001); the usual disclaimers apply.

${ }^{\dagger}$ Simone Bertolia, Université Clermont Auvergne, CNRS, CERDI, IUF (France). Address: simone.bertoli@uca.fr - CERDI, 26 avenue Léon-Blum, F-63000, Clermont-Ferrand, France.

Frederic Docquier, LISER (Luxembourg), IRES-FNRS, UC Louvain (Belgium), FERDI (France)

Address: frederic.docquier@liser.lu - LISER, Maison des Sciences Humaines, 11 Porte des Sciences, L-4366 Esch-sur-Alzette, Luxembourg;
}

Hillel Rapoport, Paris School of Economics - Université Paris I Panthéon-Sorbonne (France) and CEPII

Address: hillel.rapoport@psemail.eu - PSE, Campus Jourdan, 48 boulevard Jourdan, F-75014 Paris, France.

Ilse Ruyssen, CESSMIR, Ghent University and IRES, UC Louvain (Belgium).

Address: ilse.ruyssen@ugent.be - Department of Economics, 2 Tweekerkenstraat, B-9030 Gent, Belgium. 


\section{Abstract}

We use a multilevel approach to characterize the relationship between weather shocks and (internal and international) migration intentions. We combine individual survey data on migration intentions with measures of localized weather shocks for Western African countries over 2008-2016. A meta-analysis on results from about 310,000 regressions is conducted to identify the specification of weather anoma-lies that maximizes the goodness of fit of our empirical model. We then use this best specification to document heterogeneous mobility responses to weather shocks, which can be due to differences in long-term climatic conditions, migration percep- tions, or adaptation capabilities. We find that droughts are associated with a higher probability of migration intentions in Senegal, Niger and Ivory Coast. The effect on international migration intentions are only significant in Niger. These effects are amplified, but qualitatively similar, when restricting the sample to rural low-skilled respondents.

\section{Keywords}

International Migration, Migration intentions, Individual-level Data, Weather Shocks, Western Africa.

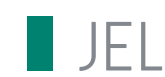

F22, J61, 013, 015.

\section{Working Paper}

\section{CEPY}

CEPII (Centre d'Etudes Prospectives et d'Informations Internationales) is a French institute dedicated to producing independent, policyoriented economic research helpful to understand the international economic environment and challenges in the areas of trade policy, competitiveness, macroeconomics, international finance and growth

CEPII Working Paper
Contributing to research in international
economics
@ CEPII, PARIS, 2020
All rights reserved. Opinions expressed
in this publication are those of the
author(s) alone.

Editorial Director: Sébastien Jean

Production: Laure Boivin

Published on March 5, 2020

No ISSN: $1293-2574$
CEPII

20, avenue de Ségur TSA 10726 75334 Paris Cedex 07 +33153685500 www.cepii.fr Press contact: presse@cepii.fr 


\section{Introduction}

There is strong evidence that changes in weather conditions can substantially impact economic, health and welfare outcomes in the affected regions (Dell et al., 2014). In particular, variations in temperature or rainfall have strong impacts on the level and volatility of income in agriculture-dependent economies, thereby increasing incentives (and sometimes forcing) individuals and families to seek more viable and less vulnerable places to live (IPPC, 2014; Rigaud et al., 2018). Climatic conditions have been a determinant of human migration since the beginning of humanity. For example, Fagan (2008) finds that the $2^{\circ} \mathrm{C}$ rise in temperatures during the Medieval warm period (between the $9^{\text {th }}$ and $14^{\text {th }}$ century) resulted in large relocations of people and economic activity. ${ }^{1}$ In spite of a growing availability of data on weather shocks and on human mobility, important gaps remain in our understanding of the complex nexus between climate shocks and migration. ${ }^{2}$ This is mainly due to $(i)$ the difficulty in connecting weather shocks realizations to the relevant exposed populations, and $(i i)$ the difficulty in accounting for the individual and regional contexts that govern mobility decisions. Existing studies analyzing the climatemigration nexus either at the aggregate or at the individual level suffer from important inherent limitations (Piguet, 2010). Macroeconomic approaches are usually constrained by the fact that migration data are available at coarse levels of temporal and spatial granularity. Correlations measured at an aggregate spatial level might not hold true at the local level (e.g., nothing guarantees that people who emigrated from a wide area under environmental stress were actually subject to it). In addition, a limitation of lowfrequency macrodata is that they might capture country-specific, time-varying factors such as institutional shocks taking place over the period of analysis, which influence emigration and, by pure coincidence, are correlated with changes in weather conditions. As far as individual survey and census data are concerned, they suffer from the difficulty to keep track of international migrants and usually include a low-frequency panel dimension. Conducting a survey takes time, implying that the date of the interview varies across individuals and is imprecisely connected to the timing of weather realizations.

To bridge the gap between the two approaches and to leverage on their respective strengths, our paper uses a multilevel approach. We combine measures of climate shocks collected from ground weather stations at a relatively detailed level of time and spatial granularity, with individual survey data documenting migration intentions at specific dates in specific spatial units. Our database covers six Western African countries (Burkina Faso, Ivory Coast, Mali, Mauritania, Niger, Senegal) over a period of up to nine years. The multilevel approach allows us to better identify individuals hit by climate shocks, and to gain understanding of the mechanics of migration responses. It has been used in a few studies focusing on internal migration (Gray and Mueller, 2012a; Mueller et al., 2014); we use this approach to shed light on intentions to move internally or internationally and on how to model them.

We conduct the empirical analysis in two steps. First, taking advantage of a large degree of freedom to define the specification of the migration response function, we compare a large set of empirical specifications connecting migration intentions to climate shocks. Considering two dependent variables (i.e., intentions to move within 12 months, and in-

\footnotetext{
${ }^{1}$ See also Boustan et al. (2012) on internal migration responses to natural disasters in the US during the 1920 s and 1930s, and on the role of public investments for protection against flooding.

${ }^{2}$ Recent literature surveys are provided in Piguet et al. (2011), Millock (2015), Berlemann and Steinhardt (2017), and Cattaneo et al. (2019).
} 
tentions to migrate internationally), our specifications differ in the choice of the weather variables (temperature, precipitation, or standardized precipitation evapotranspiration indices), the direction of the shock (adverse, beneficial, or both), the intensity of the shock (one or two relative standard deviations from the long-term mean), ${ }^{3}$ the length of the period over which shocks are identified (from 1 to 36 months prior to the date of the interview), and the treatment of the (local) crop-growing seasons. For each specification, we estimate the sensitivity of migration intentions to climate shocks using country-specific logit models and controlling for individual characteristics. Overall, we run about 310,000 logit regressions, and then conduct a meta-analysis of the regression results to assess the impact of methodological choices on migration responses (at the extensive and intensive margins), and of the predictive power of the model. This meta-analysis reveals that the predictive power of the model is maximized when using negative SPEI shocks (i.e., droughts), when measuring shocks as the share of months with at least 2 relative standard deviations below the local SPEI long-term value over the last 12 months, and focusing on the crop-growing season. Moreover, the model performs better when focusing on the subsample of individuals living in rural areas.

Second, we use this preferred specification to analyze the determinants of migration intentions, and to test whether these intentions are affected by adverse weather shocks in the six Western African countries under consideration. The results vary drastically across countries, which probably reflects unobserved cultural differences, heterogeneous longterm climate conditions, and heterogeneous capabilities to adapt to weather anomalies. ${ }^{4}$ We find that a larger share of months characterized by a drought in the crop-growing season compared to the previous 12 months is associated with a higher probability of intending to move within 12 months in Senegal, Niger, and Ivory Coast. Insignificant results are found for Burkina Faso, Mali and Mauritania. When focusing on international migration intentions, the same drought episodes are associated with a higher probability of emigrating from Niger only, suggesting that adverse weather shocks mostly affect intentions to move locally. ${ }^{5}$ These effects are amplified, but qualitatively similar, when restricting the sample to low-skilled respondents from rural areas.

Our study is unique in several respects. First, we focus on Western Africa, a region which is usually seen as one of the most "at risk" regions of the world in terms of environmental balance and associated mobility patterns (European Commission, 2015), that is heavily depending on agriculture, and that has already experienced rising temperatures, shifting precipitation patterns, and increasingly extreme events (Jalloh et al., 2013). Second, we examine migration intentions both domestically and internationally. While migration intentions do not translate systematically into actual migration flows, the two appear strongly correlated (Bertoli and Ruyssen, 2018). Third, we analyze responses to several types of climate shocks, shed light on the nexus between climate shocks and emigration decisions, and provide methodological recommendations to formalize these links. Our analysis can be easily generalized to other countries, regions or continents.

The rest of the paper is structured as follows: Section 2 describes the various strands of

\footnotetext{
${ }^{3}$ We define a relative standard deviation as the ratio between an absolute standard deviation and the long-term mean of the relevant climate variable.

${ }^{4}$ Existing studies suggest that the relationship between climate change and migration is highly contextspecific. Our approach allows for identifying whether this finding is governed by migration intention responses. The complementary explanation would be that the probability and timing of the realization of migration intentions are context-specific.

${ }^{5}$ Burzynski et al. (2019) reach the same conclusion when focusing on mobility responses to long-term climate change (i.e., long-term trends in temperature and rising sea level).
} 
literature to which our paper relates. Section 3 introduces the different data sources that we use in the empirical analysis, and provides the relevant descriptive statistics. Section 4 describes the econometric model and discusses the results of our meta-regression analysis. Section 5 presents the results of our benchmark model and a few variants for the six Western African countries. Finally, Section 6 provides concluding remarks.

\section{Related literature}

Our paper speaks to the literature on climate change and migration, and to the literature on the determinants of migration intentions.

The literature on climate change and migration has produced mixed results, especially in cross-country settings. ${ }^{6}$ Marchiori et al. (2012) show that weather anomalies in sub-Saharan Africa tend to increase rural-to-urban migration through a decrease in agricultural productivity. They also find that this urbanization process induces a downward pressure on income in cities, which in turn induces internationally mobile workers to move to other countries. ${ }^{7}$ In the same vein, Beine and Parsons (2015) find that natural disasters increase urbanization in developing countries; they also identify some indirect effects on international outflows through a decrease in income in urban areas. Marchiori et al. (2015) show that weather-related income variability has little effect on migration decisions. On the contrary, Coniglio and Pesce (2015) and Backhaus et al. (2015) show that higher variability in rainfalls leads to outmigration to OECD countries. Cai et al. (2016) find that increases in the level of temperatures boost outmigration to OECD destinations from agriculturally-dependent countries. In contrast, Cattaneo and Peri (2016) report that a gradual increase in the level of temperature only boosts international and rural-to-urban migrations in middle-income countries but reduce migration outflows from poor countries.

The disparity in these results is at least partly due to the lack of an integrated approach, which relates to the scarcity, quality, and coarse spatial aggregation of the data. It also reflects the confluence of factors that cannot be identified separately: the migratory mechanisms involved, the structure of the economy, and the behavioral assumptions about household decisions. ${ }^{8}$ Nonetheless, cross-country studies strongly suggest that internal and international migration responses to climate shocks are context-specific. In particular, they depend on the type of economic activity and on the level of development of the country under consideration, without it being possible to assert whether such conditional effects are due to financial constraints, to the skill composition of the population, to heterogeneous capabilities of "on-farm" adaptation, to past migration experiences, or even to cultural characteristics governing the perceptions of environmental hazards.

Case studies conducted at the microeconomic level tend to confirm that migration responses are highly heterogeneous (Gray and Bilsborrow, 2013; Piguet, 2010). Due to data constraints, case studies usually focus on the impact of a single type of shock (e.g.,

\footnotetext{
${ }^{6}$ Cross-country studies tend to focus on internal migration responses using urbanization rates (Barrios et al. 2006) or data aggregated by region (e.g., Bohra-Mishra et al. (2014) on province-to-province movements in Indonesia, or Bazzi (2017) on village-to-village movements, again in Indonesia).

${ }^{7}$ This is consistent with the results in Girsberger et al. (2019) who investigate the effect of migration to the main urban centers of francophone West Africa on wages and wage inequality in that region.

${ }^{8}$ Cattaneo and Peri (2016) argue that the disparity in the results can be due to the fact that some studies are overcontrolling with variables that are also influenced by weather at origin, and that the effects of weather variables vary with income per capita at origin.
} 
drought, high temperatures, low precipitation, natural disasters) and on rural-to-urban migration in specific countries. The role of household wealth also varies across countries. Just to name a few examples, Gray and Mueller (2012a) use longitudinal survey data spanning over 15 years to estimate the mobility responses to flooding and crop failures in Bangladesh. They find significant effects for women and for the poorest segments of the population. Looking at the case of Pakistan, Mueller et al. (2014) combine satellitederived measures of climate shocks with longitudinal survey data. They find that flooding has modest to insignificant impacts on migration, while heat stress episodes increase the long-term migration of men, and more so for land- and asset-poor families. In contrast, other studies suggest that liquidity constraints prevent profitable migration in poor households. Bazzi (2017) combines administrative data available at the village level in Indonesia with rainfall shocks. He finds that liquidity constraints limit migration responses. The implied migration costs are suggestive of large inter-regional differences in the prevalence of financial constraints as well as in the potential net income gains from migration. Using South-African census data, Mastrorillo et al. (2016) quantify the effect of temperature and rainfall shocks on inter-district migration flows. They find that increases in temperatures and (negative or positive) anomalies in rainfalls enhance out-migration of blacks, low-income individuals while the effect on white, high-income individuals is either weak or insignificant.

Other related studies highlight differences across skill groups. Due to heterogeneous exposure to climate change, Thiede et al. (2016) find that households with little or no education are more likely to be displaced by climate shocks than individuals with completed primary education. Their analysis relies on 25 censuses collected in eight South-American countries and contradicts panel data analyses relying on international migration flow data (Drabo and Mously Mbaye, 2015). The role of gender is also controversial. While Thiede et al. (2016) and Gray and Bilsborrow (2013) find large migration responses for women, most of the existing studies show that men are more responsive than women, especially when looking at long-distance migration (Dillon et al., 2011) or when accounting for marriage-related moves (Gray and Mueller, 2012b).

In general, methodological choices are strongly affecting the results (Beine and Jeusette, 2018). Moreover, quantifying international migration responses using survey data is a complex task since international migrants disappear from (or are imperfectly captured in) census and register statistics, especially when the entire household is moving (Ibarraran and Lubotsky, 2018). ${ }^{9}$ One distinctive feature of our analysis is that we focus on internal and international migration intentions, the realization of which takes time. Our conjecture is that potential migrants remain in the pool of respondents in the first months following a shock. There is a large number of case studies in sociology and demography investigating the determinants of migration intentions (among others, see Becerra (2012); Drinkwater and Ingram (2009); Jonsson (2008); Wood et al. (2010)). Comparative survey data on migration intentions, together with rich information on the individual characteristics of respondents, come from the Gallup World Polls (GWP), a unique database covering 150 countries since the year 2008. GWP includes "finer" (i.e., sub-regional) and "coarser" regional identifiers as well as interview dates, which allow us to connect respondents with spatial and time variations in weather conditions.

As the data are relatively new, the literature relying on these data to capture migration

\footnotetext{
${ }^{9}$ Two additional sources of under-counting of international migration episodes in population censuses and surveys concern deliberate mis-reporting (Hamilton and Savinar, 2015) and the dissolution of the household of origin of the migrant (Bertoli and Murard, 2020).
} 
intentions is limited. Manchin et al. (2014) investigate the impact of individual wellbeing on the willingness to migrate internationally and locally. Dustmann and Okatenko (2014) study the role of wealth constraints and local amenities in governing migration intentions from sub-Saharan African countries. Docquier et al. (2014) and Dao et al. (2018) study the determinants of migration intentions after aggregating GWP data by country pair and by education level. Docquier et al. (2015) use the GWP data to proxy the number of potential migrants who could respond to a relaxation of migration policy barriers. Bertoli and Ruyssen (2018) and Manchin and Orazbayev (2018) quantify the effect of migrant networks on migration intentions and on migrants' destination choices. Ruyssen and Salomone (2018) investigate whether gender discrimination fosters women's migration intentions and plans. Docquier et al. (2019) investigate whether would-be migrants from MENA countries self-select on cultural traits such as religiosity and gender attitudes. Finally, Friebel et al. (2018) study the elasticity of migration intentions to illegal moving costs, exploiting the demise of the Gaddafi regime in 2011 and the ensuing opening of the Libyan route to Europe as a quasi-natural experiment. To the best of our knowledge, our paper is first to connect the GWP data on migration intentions with weather shocks and to conduct the analysis at relatively low levels of spatial resolution.

\section{Data sources and descriptives}

Our analysis covers six Western African countries (Burkina Faso, Ivory Coast, Mali, Mauritania, Niger and Senegal) over a period of nine years, from 2008 to 2016 . We use micro data on migration intentions of individuals aged 15 to 49 for whom we also have a rich set of individual variables. We connect these data from the GWP surveys with data on adverse weather shocks (or anomalies) at the regional level, at two levels of resolution (for each region we will use either a "fine" or a "coarse" regional identifier, depending on the set of regional characteristics we control for). This section describes our data sources and provides descriptive statistics.

Migration intentions. - The Gallup World Polls (GWP) are surveys conducted by Gallup on around 1,000 randomly selected individuals in each wave, either through phone calls or through face-to-face interviews in countries where less than 80 percent of the population has a telephone landline (i.e., virtually all developing countries). ${ }^{10}$ The sampling frame represents the entire civilian population aged 15 and above covering the entire country including rural areas, but excluding areas where the safety of the interviewing staff might be threatened, scarcely populated islands in some countries, and areas that interviewers can reach only by foot, animal, or small boats. The questionnaire of the GWP includes a core set of questions that are covered in each country-wave pair and another set of questions that are asked only in some countries and/or waves. Notably, the GWP include two related questions on the intention to move: ${ }^{11}$

\footnotetext{
${ }^{10}$ For a description of the methodology and codebook, see Gallup (2017). In some large countries such as China, India and Russia as well as in major cities or areas of special interest, over-samples are collected resulting in larger total numbers of respondents.

${ }^{11}$ The way in which such hypothetical questions are interpreted might vary across countries, as observed by Clemens and Pritchett (2016) who underlines the risk of using contingent value surveys. Typically, respondents may interpret "opportunity" in light of the possibilities currently available to them (legal migration, irregular life-threatening trip, with or without funding, etc.), which vary across regions. For this reason, we only exploit within-country variation in the econometric analysis.
} 
1. In the next 12 months, are you likely or unlikely to move away from the city or area where you live?

2. Ideally, if you had the opportunity, would you like to move permanently to another country, or would you prefer to continue living in this country?

Questions 1 and 2 differ with respect to three key dimensions, namely the time horizon of the intended move, the intended destination, and the duration of stay. Firstly, Question 1 only focuses on a short time horizon, while it does not restrict the answer to a specific (internal or international) type of destination; Question 2 does not specify a time frame for the intended move, but it restricts the focus to foreign countries. We refer to the individuals who express their intention to leave their area (or country) of residence as would be internal (or international) migrants. ${ }^{12}$ Another difference concerns the duration of the intended move, which is left unspecified in Question 1, which can thus potentially cover temporary or seasonal migration episodes as well, while Question 2 only relates to permanent moves. Many would be migrants are willing to emigrate either temporarily or permanently (Delogu et al., 2018). However, we will use Question 1 to build a proxy for the general intention to move, and Question 2 to build a proxy for the intention to migrate internationally.

Besides these key variables of interest, we also keep track of additional individuallevel information contained in the GWP. Specifically, we record respondents' age and gender at the time of the interview, whether they are highly educated or not (i.e., have completed four years of education beyond high school and/or received a 4-year college degree), whether they live in a rural or urban area (living in a rural area includes living in a farm, small town or village, while an urban area is defined as a large city or a suburb of a large city), and whether they have a distance-one connection abroad (i.e., relatives or friends who are living in another country whom they can count on for help if needed). We also have information on the number of adults (aged 15 and above) and children in the household. The GWP also include, but not for all country-wave pairs, self-reported information about household income per capita. We do not use this variable in our benchmark specification, as $(i)$ this would entail a (for some countries, substantial) reduction in our sample size, ( $i i)$ self-reported income can be affected by a substantial measurement error, especially in rural areas where subsistence agriculture is predominant, and ( iii) income is likely to be affected by climate shocks and acts as a channel of transmission governing emigration decisions, so that we would end up overcontrolling, as argued by Cattaneo and Peri (2016).

Table 1 describes the main characteristics of the GWP data, and Figure 1 illustrates some key stylized facts. Panel A of Table 1 gives the number of observations per year and per country. Our sample consists of 41,834 observations. Panel B gives the month of the interview, a variable that will be used to connect the timing of migration intentions with the timing of weather realizations. Panel $\mathrm{B}$ reveals that there is considerable variation in the period of the year in which the survey is conducted across countries and waves.

\footnotetext{
${ }^{12}$ For individuals who provide a positive answer to Question 2 (i.e., would-be international migrants), the GWP also ask the intended destination country; Bertoli and Ruyssen (2018) provide evidence that variations in bilateral migration intentions correlate with variations in actual gross bilateral migration flows to OECD countries. In addition, the GWP also include a question on migration plans: Are you planning to move permanently to another country in the next 12 months, or not? However, this question is only asked if the answer related to migrate intention is affirmative, which considerably reduces the number of observations. We will not exploit it in our analysis.
} 
Furthermore, the GWP include up to two sets of geographic identifiers (a finer and a coarser one) corresponding to the location of each respondent, which broadly follow the administrative units of each country (i.e., regional or sub-regional administrative entities). We have processed these identifiers, matching them with timely maps from Global Administrative Areas (henceforth GADM). ${ }^{13}$ This intermediate step allows us to connect each individual in the sample to the weather conditions prevailing in the GADM region(s) where the interview took place. For this step, we also use the information about the month of the interview, a relevant piece of information to ensure that we correctly match each respondent to relevant past weather conditions.

Table 1: Gallup data on migration intentions by year and by country

\begin{tabular}{|c|c|c|c|c|c|c|c|c|c|c|}
\hline \multirow[t]{2}{*}{ Country } & 2008 & 2009 & 2010 & "2011 & "2012 & 2013 & 2014 & 2015 & 2016 & \\
\hline & \multicolumn{9}{|c|}{ A. Sample size } & Total \\
\hline Burkina Faso & 873 & 0 & 821 & 836 & 808 & 859 & 845 & 835 & 890 & 6,767 \\
\hline Ivory Coast & 0 & 837 & 0 & 0 & 0 & 881 & 860 & 839 & 864 & 4,281 \\
\hline Mali & 813 & 808 & 795 & 835 & 848 & 786 & 834 & 812 & 825 & 7,356 \\
\hline Mauritania & 0 & 858 & 1,687 & 1,715 & 845 & 814 & 834 & 808 & 802 & 8,363 \\
\hline Niger & 862 & 878 & 838 & 852 & 866 & 835 & 847 & 811 & 839 & 7,628 \\
\hline \multirow[t]{2}{*}{ Senegal } & 836 & 869 & 848 & 761 & 825 & 825 & 805 & 825 & 845 & 7,439 \\
\hline & \multicolumn{9}{|c|}{ B. Month of the interview } & \#Waves \\
\hline Burkina Faso & Apr & 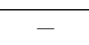 & May & Sep & May & May & May & May & Apr & 8 \\
\hline Ivory Coast & - & Apr & - & - & - & Jun & May & Jun & Apr & 5 \\
\hline Mali & Jun & Oct & Oct & Nov & Nov & Oct & Oct & Oct & May & 9 \\
\hline Mauritania & - & Sep & Mar/Sep & $\mathrm{Feb} / \mathrm{Sep}$ & Feb & Jun & Nov & Apr & Mar & 8 \\
\hline Niger & Jun & Jun & Nov & Nov & Nov & Sep & Oct & Oct & Jun & 9 \\
\hline \multirow[t]{2}{*}{ Senegal } & Apr & Jun & Apr & Apr & Apr & May & Apr & May & Mar & 9 \\
\hline & \multicolumn{9}{|c|}{ C. Availability of coarse region ID } & \#Waves \\
\hline Burkina Faso & Yes & - & Yes & Yes & Yes & Yes & Yes & Yes & Yes & 8 \\
\hline Ivory Coast & - & No & - & - & - & No & Yes & Yes & Yes & 3 \\
\hline Mali & Yes & Yes & Yes & Yes & Yes & Yes & Yes & Yes & Yes & 9 \\
\hline Mauritania & - & Yes & Yes & Yes & Yes & Yes & Yes & Yes & Yes & 8 \\
\hline Niger & Yes & Yes & Yes & Yes & Yes & Yes & Yes & Yes & Yes & 9 \\
\hline \multirow[t]{2}{*}{ Senegal } & No & No & Yes & Yes & Yes & Yes & Yes & Yes & Yes & 7 \\
\hline & \multicolumn{9}{|c|}{ D. Availability of fine region ID } & \#Waves \\
\hline Burkina Faso & No & - & No & No & No & Yes & Yes & Yes & Yes & 4 \\
\hline Ivory Coast & - & No & - & - & - & No & Yes & Yes & Yes & 3 \\
\hline Mali & Yes & Yes & Yes & Yes & Yes & Yes & Yes & Yes & Yes & 9 \\
\hline Mauritania & - & Yes & Yes & Yes & Yes & Yes & Yes & Yes & Yes & 8 \\
\hline Niger & No & No & No & No & No & No & Yes & Yes & Yes & 3 \\
\hline Senegal & Yes & Yes & Yes & Yes & Yes & Yes & Yes & Yes & Yes & 9 \\
\hline
\end{tabular}

Notes: Source: Authors' elaboration on Gallup World Polls.

Panels C and D of Table 1 indicate whether coarse and/or fine regional identifiers are available for each year and for each country. The two sets of identifiers are not necessarily available for all country-year pairs. For instance, neither of the two sets of identifiers is available before 2013 for Ivory Coast. Figures 1a and 1b plot the coarse and fine GADM regions for the six Western African countries included in our analysis. Non-colored portions of the country (notably, for Mali and Niger) correspond to areas of the country that have not been covered by the GWP in at least one year between 2008 and 2016 . Note that the various countries differ with respect to the level of disaggregation of the two sets of regional identifiers. Specifically, for Burkina Faso, the fine regional identifiers

\footnotetext{
${ }^{13}$ See https://gadm.org/.
} 
correspond to provinces, while the coarse identifiers correspond to larger administrative regions. For Ivory Coast, the GWP distinguish between districts and aggregations of districts. For Mali, the two identifiers correspond to cercles and broader regions respectively. For Mauritania, the two identifiers correspond to administrative regions and aggregation of these regions, respectively. For both Niger and Senegal, we have départements and administrative regions.

Finally, Figures $1 \mathrm{c}$ and $1 \mathrm{~d}$ map the share of respondents in each fine region who state their intention to move within 12 months and to migrate abroad, respectively. The lightcolored areas are regions where the share of intended movers is smaller than $20 \%$ (15\% for international migration intentions). The dark-color areas are regions where this share varies between 41 and $56 \%$ (between 35 and $55 \%$ for international migration intentions).

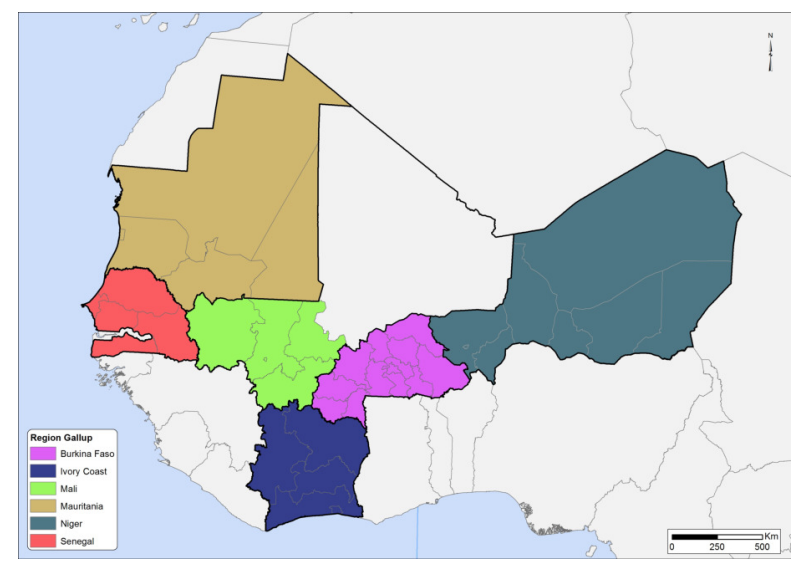

(a) Coarse regions by country

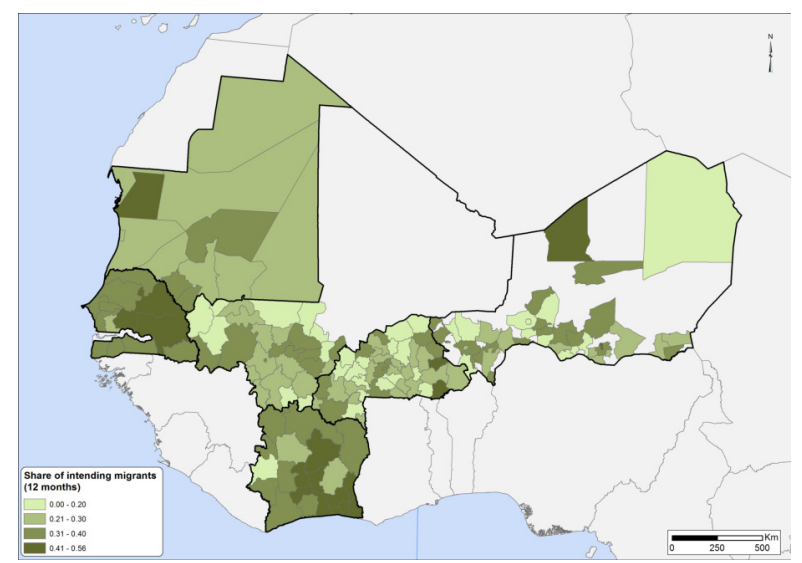

(c) Moving intentions within 12 months (fine regions)

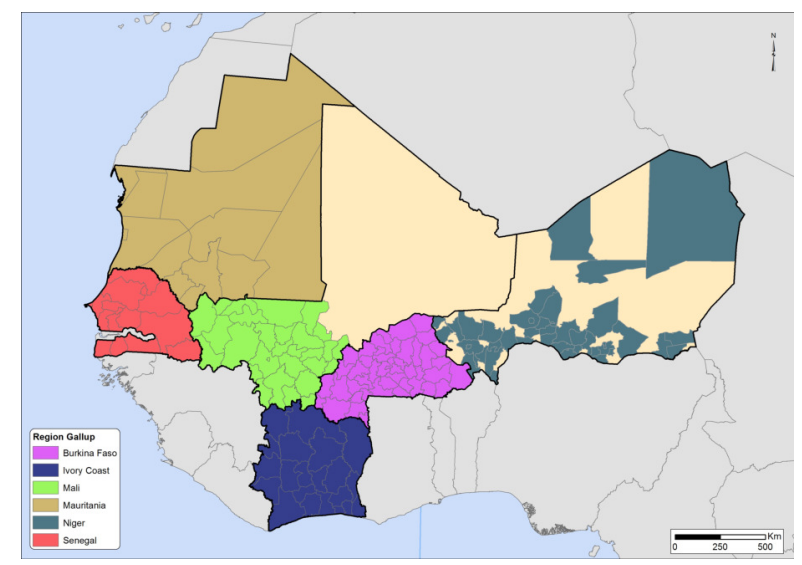

(b) Fine regions by country

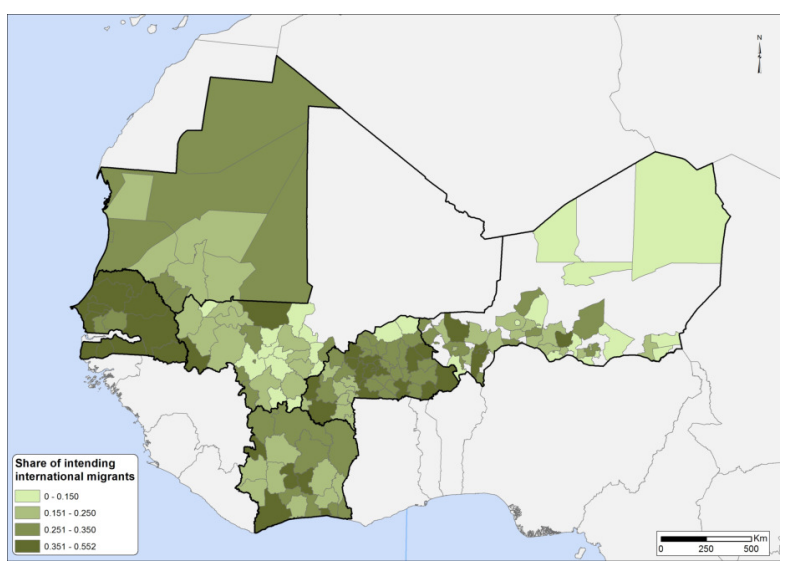

(d) International migration intentions (fine regions)

Figure 1: GWP data by region

Weather shocks. - We use data on rainfall $(P)$, on temperature $(T)$, and on the Standarized Precipitation Evapotranspiration Index (SPEI) (Begueria et al., 2014) to identify weather shocks. Data on rainfall and temperature are available by month and for each GADM region of the countries included in the analysis from the high-resolution gridded dataset CRU-TS v.4.01 built by the Climatic Research Unit of the University of East Anglia (Harris et al., 2014). The data on meteorological conditions at the monthly 
level are provided at a resolution of 0.5 degrees, ${ }^{14}$ and they come from the aggregation of observations collected from (a varying number of) ground weather stations. The weather conditions prevailing in each GADM region have been computed by aggregating the values corresponding to the grids that belong (entirely or partly) to the region, and each grid is assigned a weight that is proportional to the share of its surface that belongs to the GADM region.

More specifically, data on rainfall (temperature) come from up to eight weather stations located within a radius of $400 \mathrm{~km}(1,200 \mathrm{~km})$ from the centroid of each grid. ${ }^{15}$ For each ground weather station, the observations are first transformed into "anomalies" (i.e., distance to the long-term average value calculated over the period January 1901-December 1999). Figure 2a depicts the long-term average temperature level by "fine" region. For the six countries under consideration, the average is above $24.7^{\circ} \mathrm{C}$ in all regions. Temperatures around $30^{\circ} \mathrm{C}$ are observed in desertic areas of Mauritania, Senegal, Mali, Burkina Faso, and Niger. Figure 2c maps the average precipitation by fine region. The North region (covering a large part of Mauritania and Niger, and the uncovered part of Mali) is occupied by the Western part of the Sahara desert, where it almost never rains. The middle region is semi-arid due to the African Monsoon, which brings rainfalls in the Summer. In the Southern regions of Senegal, Mali, Burkina Faso and Ivory Coast, the rainy season is more intense and longer, and the landscape is greener.

Anomalies corresponding to stations falling within the radius are interpolated. The version 4.01 of the CRU-TS dataset relies on angular distance weighting interpolation for aggregating the anomalies (New et al., 2000): the weight associated to a station declines with its distance from the centroid (observations from closer stations are more informative) and increases with the degree of angular isolation of a station (observations from two stations that form a small angle with the centroid provide duplicated information). The interpolated value of the anomaly is then added to the long-run average for the centroid of the grid to obtain the information on temperatures or on rainfalls in a given month.

The CRU-TS dataset uses the information from all available ground weather stations at each point in time, so that the set of stations that are associated to each grid can vary over time. The dataset contains the information on the number of stations that have been used for each grid (separately for rainfall and temperature), that we have aggregated at the level of (fine and coarse) regions in the GWP data. If no ground weather station was active in a given month within the pre-specified radiuses, then the grid is assigned a zero anomaly (i.e., the reported values for temperature and rainfall coincide with the long-run average). Fluctuations in the density of ground weather stations can influence the reliability of the weather data, but they can also reflect seasonal patterns in the spatial variability of meteorological conditions which require variations in station density to keep the reliability of the data unchanged.

In practice, an adverse weather shock is defined as a month in which the mean temperature exceeds its long-term average value by more than two relative standard deviations (this threshold is guided by the meta-analysis conducted below), or a month in which the total level of precipitation is smaller than the long-term average minus two relative standard deviations. Figure $2 \mathrm{~b}$ depicts the share of months (over the period 2008-2016) with adverse relative temperature shocks. Shocks are greater in the arid and semi-arid areas of Mauritania, Senegal and Mali. Figure 2d shows the share of months with adverse

\footnotetext{
${ }^{14}$ Half a degree of latitude corresponds to approximately $55 \mathrm{~km}$ at the equator.

${ }^{15}$ The two radiuses represent the distances beyond which observations from a ground weather station become uninformative about the weather conditions prevailing in the centroid of the grid.
} 


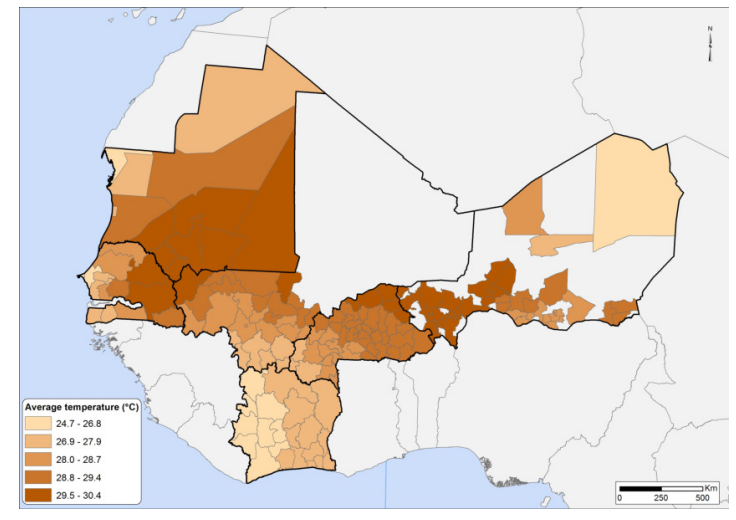

(a) Average temperature (fine regions)

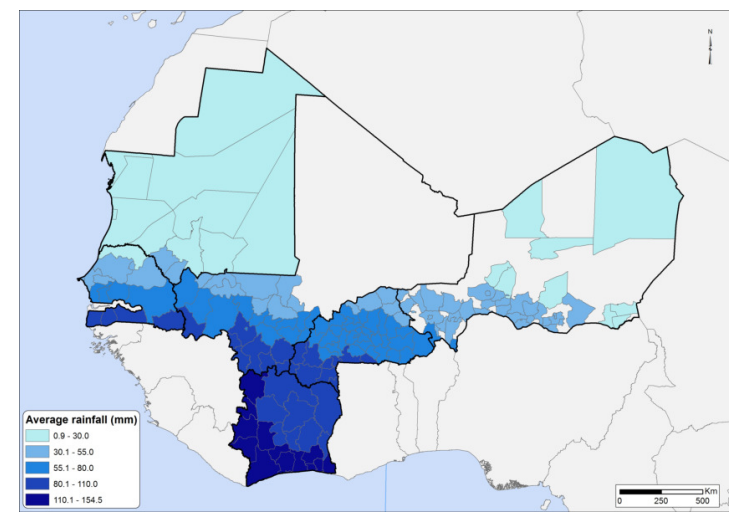

(c) Average precipitation (fine regions)

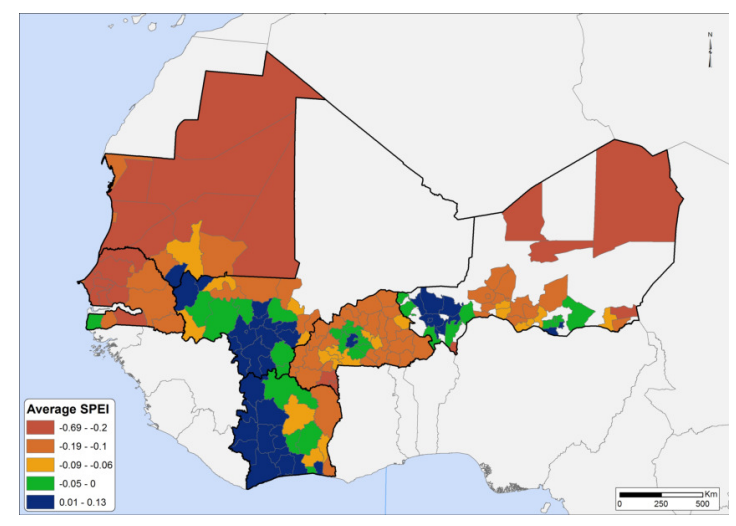

(e) Average SPEI (fine regions)

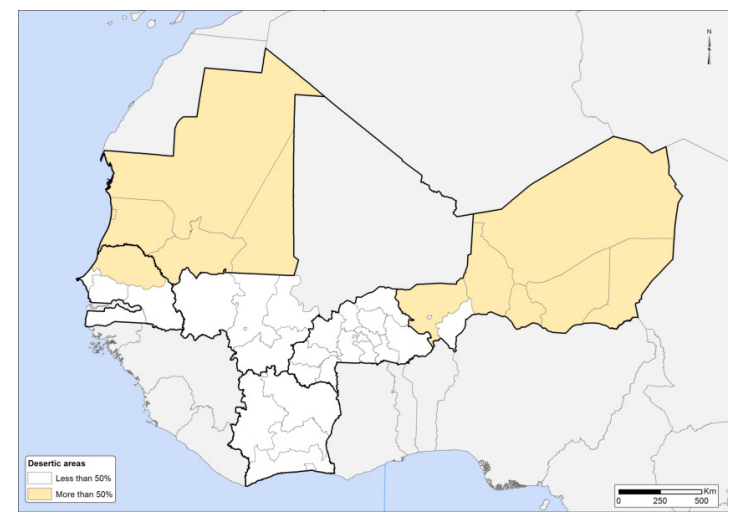

(g) Desert areas (coarse regions)

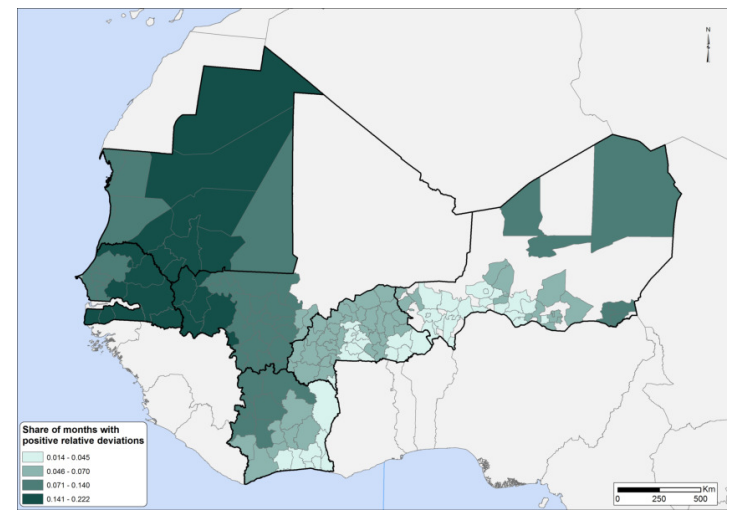

(b) Adverse temperature shocks (fine regions)

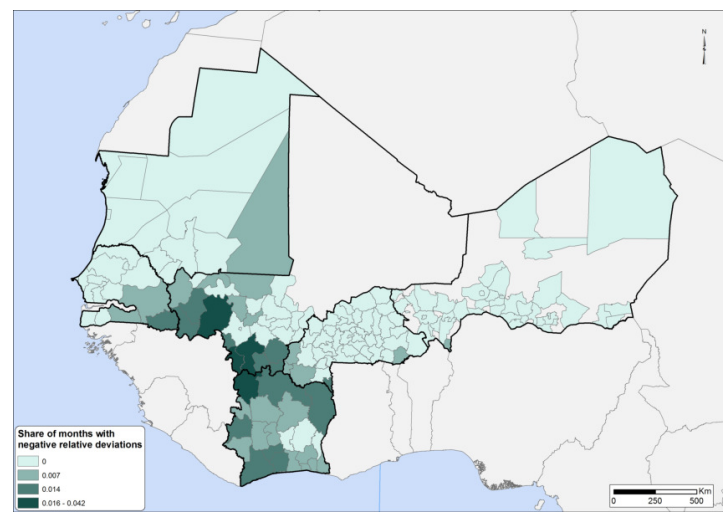

(d) Adverse precipitation shocks (fine regions)

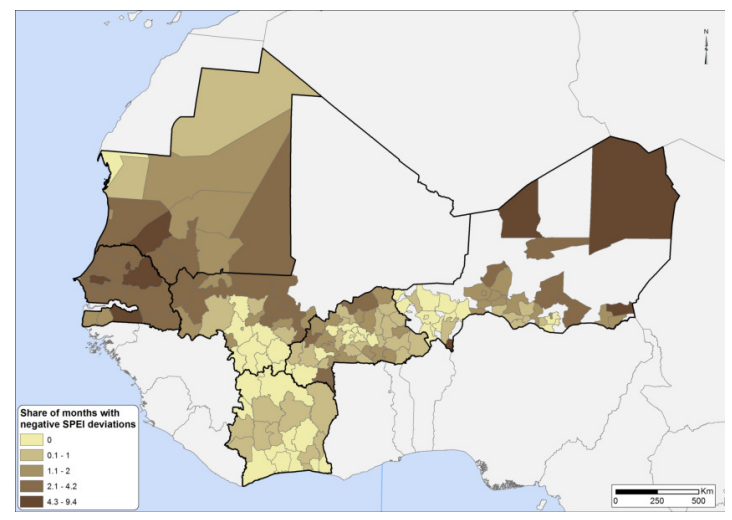

(f) Adverse SPEI shocks (fine regions)

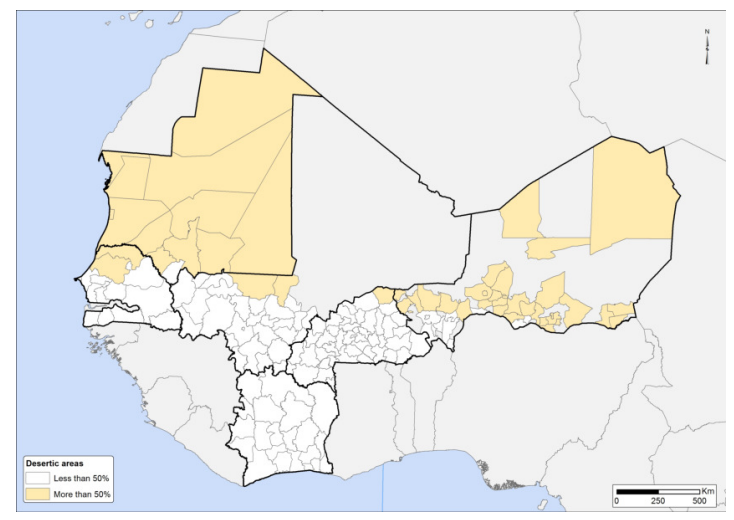

(h) Desert areas (fine regions)

Figure 2: Data on average weather conditions and adverse shocks (2 st. dev.) 
rainfall shocks, which are more frequent in the South of Mali, in Burkina Faso and in Cote d'Ivoire.

We also use information on the SPEI. This is a multiscalar drought index that is used for determining the onset, duration and magnitude of drought conditions with respect to normal conditions in a variety of natural and managed systems such as crops, ecosystems, rivers, water resources, etc. It depends both on the supply of water to the ground through rainfall, i.e., $P_{r t}$, and the demand (or use) of water by the atmosphere through evapotranspiration, i.e., $E T_{0 r t}=f\left(T_{r t}, X_{r}\right)$, where $T_{r t}$ is the temperature in region $r$ in month $t$ and $X_{r}$ is a set of other factors (such as latitude or monthly number of sun hours). Let $D_{r t} \equiv P_{r t}-E T_{0 r t}=P_{r t}-f\left(T_{r t}, X_{r}\right)$ denote the water balance in region $r$ and in period (month) $t$. The SPEI is defined over different time horizons: specifically, the $S P E I_{r t}$ is distributed according to a log-logistic distribution: ${ }^{16}$

$$
F\left(D_{r t}\right)=\left[1+\left(\frac{a}{D_{r t}-c}\right)^{b}\right]^{-1}
$$

where:

$$
D_{r t} \equiv \sum_{s=t-r+1}^{t} D_{r s}
$$

and where $a, b$ and $c$ are parameters that are estimated. The $S P E I_{r t}$ has a zero mean and a unitary variance. The distinctive advantage of the SPEI with respect to a separate reliance on rainfall or on temperature to identify extreme weather events is that this variable incorporates the interaction between these two variables in determining agricultural yields: for instance, the effect of a period with below average rainfall (or above average temperature, respectively) on agricultural output could be mitigated by a below average temperature (or above average rainfall, respectively). Differently from rainfall and temperature data, the latest available version of the SPEI is computed on the basis of an earlier version of the CRU dataset, namely Version 3.23 of the CRU-TS dataset, which is available until December 2015. ${ }^{17}$ This entails that the estimates based on the SPEI are based on a slightly more restricted sample, which excludes the last wave of the GWP.

A drought is characterized by $S P E I_{r t}<0$. The long-term average SPEI is depicted in Figure 2e. Desertic areas exhibit negative levels while the Southern regions of Mali, Burkina Faso and Cte d'Ivoire exhibit positive values. Figure $2 f$ depicts the share of months with adverse SPEI shocks. The largest shares are observed in Mauritania and in the Northern regions of Senegal, Mali and Niger, where they vary between 4.3 and $9.4 \%$.

Local crop-growing seasons. - Several studies show that the economic effects of weather shocks mostly operate through their influence on crop yields. In particular, adverse weather shocks occurring during the crop-planting and crop-growing seasons are more likely to affect crop production (Iizumi and Ramankutty, 2015). For each GADM region belonging to the six countries included in our empirical analysis, we are able to identify the main crop, and then rely on information on the (local) planting and harvesting season for this crop to identify periods of the year in which weather conditions are expected to exert stronger influence on agricultural yields, and thus possibly on stated migration

\footnotetext{
${ }^{16}$ In words, the SPEI at 3 months for January 2019 is a function of the sum of the water balance from November 2018 to January 2019.

${ }^{17}$ See http://spei.csic.es/database.html; the main difference resides in the way the anomalies from the ground weather stations are aggregated.
} 
intentions. More specifically, we proceed as follows: we rely on EARTHSTAT data to identify the main crop cultivated on the basis of a 5 minute $\times 5$ minute $(10 \mathrm{~km} \times 10 \mathrm{~km})$ latitude/longitude gridded dataset. ${ }^{18}$ We then aggregate the grid data up to the regional level, thus identifying the main crop grown in each region (e.g., groundnut, millet, rice and sorghum for the various regions in Senegal) and use a crop calendar dataset to assign planting and harvesting seasons accordingly to each region (via its main crop). ${ }^{19}$ The cropping season dataset is based on different sources that cover the 1990s or early 2000s; it allocates one value per grid and per crop. The harvested crop area data are computed using census data between 1997-2003 to obtain an average value before the start of our period of analysis. For perennial crops, such as cocoa and coffee, the growing season spans the entire year. Hence, in our empirical analysis, the adverse weather shocks illustrated in Figures 2b, 2d and 2e can be weighted by a dummy equal to one if the corresponding month belongs to the crop-planting or crop-growing season.

Note that our six Western African countries partly include arid areas of the Sahara (depicted in Figures $2 \mathrm{~g}$ and $2 \mathrm{~h}$ ). The constantly high position of the sun, the extremely low relative humidity, and the lack of vegetation and rainfall make the Saharan desert the largest continuously hot area in the world. The population consists of nomadic and pastoral people making a living from livestock breeding and trading. These people may exhibit specific mobility patterns. For this reason, we exclude regions for which the arid areas represent more than half of their surface from the sample used in our benchmark specification.

\section{Model specification}

Our goal is to analyze the determinants of migration intentions, and to test whether these intentions are affected by adverse weather shocks in the six Western African countries under consideration. This section develops the microfoundations underlying our empirical model and describes the meta-analysis used to motivate our choice of benchmark specification.

\subsection{From theory to empirics}

Consider an individual $i$, residing at time $t$ in region $r$ of country $j$. At this stage, we leave the country index aside. The choice set $D$ of individual $i$ includes her home region (which we refer to as $k=0$ without loss of generality), the rest of country, i.e., $R /\{r\}$ where $R$ is the set of regions of the country of origin (we refer to this second alternative in the choice set as $k=1)$, and the set $W$ of other countries of the world $(k=2)$. Thus, the choice set $D$ includes three alternatives: staying put, moving domestically, and migrating to an international destination. Let $V_{i k t}$ denote the utility that individual $i$ would derive from opting for alternative $k \in D$ at time $t$. We assume that this alternativespecific utility includes a deterministic component $V_{i k t}$ and a stochastic component $\epsilon_{i k t}$. If the stochastic component follows an independent and identically distributed EVT-1, or double-exponential, distribution, then the probability $p_{k t}$ that $k \in D$ will be the utility-

\footnotetext{
${ }^{18}$ See http://www.earthstat.org/harvested-area-yield-175-crops/ (accessed on December 2, 2018).

${ }^{19}$ See https://nelson.wisc.edu/sage/data-and-models/crop-calendar-dataset/netCDF5min.php (accessed on December 2, 2018).
} 
maximizing alternative is given by:

$$
p_{k t}=\frac{e^{V_{i r k t}}}{\sum_{l \in D} e^{V_{i r l t}}}
$$

The relative probability of migrating domestically over staying put is given by:

$$
\frac{p_{i 1 t}}{p_{i 0 t}}=e^{V_{i 01 t}-V_{i 00 t}}
$$

The relative probability of migrating to the foreign destination $k=2$ over staying put is given by:

$$
\frac{p_{i 2 t}}{p_{i 0 t}}=e^{V_{i 02 t}-V_{i 00 t}}
$$

The relative probability of intending to move (irrespective of the destination) over staying put is given by:

$$
\frac{p_{i 1 t}+p_{i 2 t}}{p_{i 0 t}}=e^{V_{i 01 t}+V_{i 02 t}-V_{i 00 t}}
$$

Relative choice probabilities are solely determined by the difference in the levels of utility associated to each pair of alternatives (and not by the levels themselves); this, in turn, entails that we can normalize the utility associated to the baseline option (staying) to zero. Thus, the estimated coefficient for all the regressors give us the differential effect of each variable on the attractiveness of moving versus staying.

Let $d_{i r t}^{\text {move }}$ and $d_{i r t}^{\text {abroad }}$ represent two dummy variables taking the value one if individual $i$ residing in region $r$ and interviewed at time $t$ expresses respectively the intention to move within 12 months (to an unspecified location) or the intention to move abroad (within an unspecified time horizon). We estimate logit models separately for each country:

$$
\operatorname{Pr}\left(d_{i r t}=1\right)=\frac{e^{V_{i r t}}}{1+e^{V_{i r t}}}
$$

where $d_{\text {irt }}=\left\{d_{\text {irt }}^{\text {move }}, d_{\text {irt }}^{\text {abroad }}\right\}$.

Denoting the country-of-origin index by $j$, the reduced-form expression for the utility differential between moving options and staying writes as: ${ }^{20}$

$$
V_{i r j t}=\alpha_{j}+\gamma_{j} X_{i}+\beta_{j} W S_{r t}+\delta_{j 1} d_{m}+\delta_{j 2} d_{y}+\delta_{j 3} d_{r}
$$

where individual-specific controls $\left(X_{i}\right)$ include dummies for age groups (with 15 to 24 being the omitted category) and for males, a dummy for being highly (i.e., college) educated, a dummy for living in an urban area, a dummy for having a distance-one connection abroad (i.e., a friend or family member whom one can count on when needed) and two continuous variables describing the size of the household and the number of children in the household to which individual $i$ belongs. The variable $W S_{r t}$ represents the preferred specification of our measure of past weather shocks defined for region $r$ at time $t$. The choice of $W S_{r t}$ will be the focus of the meta-analysis of the next sub-section.

Our specification of the deterministic component of the utility associated to moving also includes dummies for the month-of-the-year $m\left(d_{m}\right)$ and for the year $y$ in which

\footnotetext{
${ }^{20}$ To avoid cluttering the notation, we omit the dependency of the estimated coefficients with respect to the choice of the dependent variable; all coefficients clearly vary depending on whether $d_{i r j t}=d_{i r j t}^{12}$ or $d_{i r j t}=d_{i r j t}^{\text {abroad }}$ in Eq. (5).
} 
individual $i$ was interviewed $\left(d_{y}\right)$ to control respectively for possible seasonal effects in the stated intentions to migrate and for time-varying country-level determinants of these intentions, and a dummy for the region $\left(d_{r}\right)$ to control for time-invariant spatial heterogeneity in the intentions to move.

If the estimated coefficient $\widehat{\beta}_{j}$ associated to the weather shock measure is positive and significant, this means that weather shocks make the origin location relatively less attractive than intended destinations. The marginal effect on the probability of intending to move is given by $\widehat{\beta}_{j} p_{i j k t}\left(1-p_{i j k t}\right)$, with $k=1,2$ depending on the choice of the dependent variable, while $\widehat{\beta}_{j}$ itself represents the partial derivative of the logarithm of the relative choice probability with respect to our variable of interest.

The econometric analysis is conducted on prime-age individuals (i.e., between 15 and 49 years old); each individual is matched to the (past) weather conditions prevailing in the GADM region in which he or she is interviewed. The sample is also restricted to individuals for whom at least a coarse regional identifier is available. In the baseline specification, we match individuals to weather conditions using the finest available regional identifier (i.e, we always use fine regions if they are available, and we only resort to coarse identifiers if the former are not available). ${ }^{21}$ As already mentioned, we exclude from the sample the regions with more than 50 percent of their surface area classified as desert.

\subsection{Meta-analysis}

We have a large degree of freedom to define the specification of the response functions in general, and the definition of the weather shock variable $\left(W S_{r t}\right)$ in particular. To better understand the link between weather shocks and migration intentions, we consider a large number of specifications and conduct a meta-analysis of the regression results to assess the impact of methodological choices on migration responses at the extensive and intensive margins. For both dependent variables (intention to move within 12 months and intention to migrate abroad), our set of specifications covers different ways of measuring weather shocks, and different sub-samples of respondents. Letting $\widehat{\beta}$ represent the estimated coefficient for weather shocks, we analyze whether the various analytical choices related to our variable of interest and of sub-sample are governing its significance and/or size through a meta-regression analysis. Results for the intention to move within 12 months are reported in Table 2, while results for the intention to migrate abroad are reported in Table 3.

In particular, our meta-analysis distinguishes between: ${ }^{22}$

- Six Western African countries; we will use Burkina Faso as reference country.

- Seven weather variables of interest: deviations from the long-term trends in temperature (our reference in Tables 2 and 3 ) or in precipitations, and 5 variants of the SPEI shocks (5 methods to compute the long-term trend);

\footnotetext{
${ }^{21}$ Notice that this entails that for two countries (Burkina Faso and Mali) individuals interviewed in different waves are matched to (past) weather conditions with a varying level of precision.

${ }^{22}$ Some of the characteristics of the various specifications that we bring to the data that we consider in our meta-regressions are not covered by Beine and Jeusette (2018), who code around 80 variables for 45 papers on the relationship between weather conditions and migration; in particular, we analyze whether the significance, sign and size of the estimated coefficient for our variable of interest, i.e., $W S_{r t}$, depend on the length of the period over which we measure weather conditions, and on the thresholds that are set to identify extreme weather events.
} 
- Three types of weather shocks: both bad and good shocks taken in a symmetric way (our reference in Tables 2 and 3), adverse shocks only, or beneficial shocks only;

- Three measures of the intensity of the shock: at least one standard deviation from the long-term average (our reference in Tables 2 and 3), 2 standard deviations, or 3 standard deviations;

- Thirty-six possibilities for the length of the period over which deviations from the long-term average are computed (from 1 to 36 months);

- Two specifications: identifying weather anomalies in all months (our reference in Tables 2 and 3), or in months falling in the crop-growing season;

- Two sets of regional identifiers: finer or coarser GWP identifiers.

- Seven samples: full sample (our reference in Tables 2 and 3), or subsamples covering only rural areas, urban areas, low-educated respondents, high-educated respondents, respondents with a distance-one connection abroad (i.e., a family member or friend), and respondents without a distance-one connection abroad.

The last point in this list requires that we flag a warning: when we re-estimate our two logit models on sub-samples of observations (defined, for instance, on the basis of the level of education), we obtain a partition of the two samples into two parts of markedly different sizes. This, in turn, entails that (simply because of statistical power) the odds of finding a significant effect of past weather conditions on, say, highly-educated individuals residing in rural areas, are smaller than the odds of finding a significant effect for low-educated individuals.

Exploring all combinations involves conducting 381,024 separate regressions, and only 308,389 are converging for the intention to move within 12 months $(307,548$ for the intention to migrate abroad). In col. 1 , we identify the variables affecting the probability that $\widehat{\beta}$ cannot be estimated $(\widehat{\beta} \nexists)$; unidentified coefficients are usually due to small sample size. This problem arises in 90,794 specifications. We then focus on the 211,125 cases for which $\widehat{\beta}$ can be estimated and study the determinants of its magnitude and precision. In col. $2-4$, we identify the conditions under which $\widehat{\beta}$ is significantly different from zero $(\widehat{\beta})$, is significant and positive $(\widehat{\beta}>0)$, or significant and negative $(\widehat{\beta}<0)$, respectively. In col. 5 , we analyze whether the magnitude $(|\widehat{\beta}|)$ of the estimated effect also depends on other characteristics of the model that we bring to the data. For the latter regression, we weigh observations by the inverse of the standard error of the coefficient in order to give higher weights to highly significant values of $\widehat{\beta}$.

Maximizing the size or the significance of $\widehat{\beta}$ is not an objective per se. Hence, in col. 6 , we go beyond an exclusive focus on our variable of interest by analyzing a measure of the overall goodness of fit of each specification of the model, which also depends on the ability of other individual-level regressors to help us predict migration intentions. Specifically, let $\widehat{p}_{i}$ be the predicted probability that individual $i$ intends to migrate, and let $D_{i}$ represent a dummy variable taking the value one if individual $i$ has stated an intention to migrate. We consider that our model correctly predicts migration intentions when $\widehat{p}_{i} \geq 0.5$ and $D_{i}=1$, or $\widehat{p}_{i}<0.5$ and $D_{i}=0$. For each specification of our logit model, we can thus compute the share of observations in the sample that have been correctly predicted, and regress it on the characteristics of the model. The latter results govern the choice of our benchmark specification. 
Table 2: Meta-analysis on intentions to move within 12 months

\begin{tabular}{|c|c|c|c|c|c|c|}
\hline & $\beta \bar{\beta}$ & $\beta^{*}$ & $\overline{\beta^{*}>0}$ & $\overline{\beta^{*}<0}$ & $\left|\beta^{*}\right|$ & Predict \\
\hline \multirow[t]{2}{*}{ Adverse } & $0.446^{* * *}$ & $0.082^{* * *}$ & $0.086^{* * *}$ & $-0.004^{* *}$ & $0.341^{* * *}$ & $-0.023^{*}$ \\
\hline & $(0.002)$ & $(0.002)$ & $(0.002)$ & $(0.002)$ & $(0.011)$ & $(0.013)$ \\
\hline \multirow[t]{2}{*}{ Beneficial } & $0.263^{* * *}$ & $0.133^{* * *}$ & $0.031^{* * *}$ & $0.102^{* * *}$ & $-0.175^{* * *}$ & -0.022 \\
\hline & $(0.002)$ & $(0.003)$ & $(0.002)$ & $(0.002)$ & $(0.010)$ & $(0.013)$ \\
\hline \multirow[t]{2}{*}{ Precipitation } & $-0.158^{* * *}$ & $-0.148^{* * *}$ & $-0.110^{* * *}$ & $-0.038^{* * *}$ & $-0.505^{* * *}$ & -0.034 \\
\hline & $(0.005)$ & $(0.006)$ & $(0.004)$ & $(0.004)$ & $(0.030)$ & $(0.031)$ \\
\hline \multirow[t]{2}{*}{ SPEI } & $-0.032^{* * *}$ & $-0.126^{* * *}$ & $-0.097^{* * *}$ & $-0.029^{* * *}$ & $-0.438^{* * *}$ & $0.957^{* * *}$ \\
\hline & $(0.004)$ & $(0.004)$ & $(0.003)$ & $(0.003)$ & $(0.023)$ & $(0.023)$ \\
\hline \multirow[t]{2}{*}{ Intens. 2 sd } & $-0.170^{* * *}$ & $0.027^{* * *}$ & $0.027^{* * *}$ & 0.000 & $0.106^{* * *}$ & $0.046^{* * *}$ \\
\hline & $(0.002)$ & $(0.003)$ & $(0.002)$ & $(0.002)$ & $(0.010)$ & $(0.013)$ \\
\hline \multirow[t]{2}{*}{ Intens. 3sd } & $-0.222^{* * *}$ & $-0.017^{* * *}$ & $-0.027^{* * *}$ & $0.009^{* * *}$ & $-0.127^{* * *}$ & $-0.037^{* * *}$ \\
\hline & $(0.002)$ & $(0.002)$ & $(0.002)$ & $(0.002)$ & $(0.009)$ & $(0.014)$ \\
\hline \multirow[t]{2}{*}{ Length 12} & $0.078^{* * *}$ & $0.006^{* * *}$ & $0.009^{* * *}$ & -0.003 & 0.003 & $0.157^{* * *}$ \\
\hline & $(0.002)$ & $(0.002)$ & $(0.002)$ & $(0.002)$ & $(0.008)$ & $(0.011)$ \\
\hline \multirow[t]{2}{*}{ Length 13-24 } & $0.022^{* * *}$ & $-0.007^{* * *}$ & $0.003^{*}$ & $-0.009^{* * *}$ & $0.029^{* * *}$ & $-0.024^{* *}$ \\
\hline & $(0.002)$ & $(0.002)$ & $(0.001)$ & $(0.002)$ & $(0.009)$ & $(0.011)$ \\
\hline \multirow[t]{2}{*}{ Crop season } & $0.007^{* * *}$ & $-0.009^{* * *}$ & $-0.006^{* * *}$ & $-0.003^{*}$ & $-0.015^{* *}$ & -0.017 \\
\hline & $(0.002)$ & $(0.002)$ & $(0.001)$ & $(0.001)$ & $(0.007)$ & $(0.011)$ \\
\hline \multirow[t]{2}{*}{ Rural } & $0.007^{* *}$ & $0.010^{* * *}$ & $0.005^{* *}$ & $0.005^{*}$ & -0.006 & $0.814^{* * *}$ \\
\hline & $(0.003)$ & $(0.003)$ & $(0.002)$ & $(0.003)$ & $(0.012)$ & $(0.020)$ \\
\hline \multirow[t]{2}{*}{ Urban } & $0.028^{* * *}$ & $0.052^{* * *}$ & $0.020^{* * *}$ & $0.032^{* * *}$ & $-0.065^{* * *}$ & $-2.084^{* * *}$ \\
\hline & $(0.003)$ & $(0.003)$ & $(0.003)$ & $(0.003)$ & $(0.013)$ & $(0.020)$ \\
\hline \multirow[t]{2}{*}{ College grads } & $0.085^{* * *}$ & $-0.032^{* * *}$ & -0.001 & $-0.031^{* * *}$ & $0.060^{* * *}$ & $-0.351^{* * *}$ \\
\hline & $(0.003)$ & $(0.003)$ & $(0.002)$ & $(0.002)$ & $(0.018)$ & $(0.017)$ \\
\hline \multirow[t]{2}{*}{ Less educated } & 0.000 & 0.004 & 0.001 & 0.003 & $-0.021^{*}$ & $0.051^{* * *}$ \\
\hline & $(0.003)$ & $(0.003)$ & $(0.002)$ & $(0.002)$ & $(0.011)$ & $(0.017)$ \\
\hline \multirow[t]{2}{*}{ Network } & $0.006^{* *}$ & $-0.015^{* * *}$ & $0.006^{* * *}$ & $-0.022^{* * *}$ & $0.068^{* * *}$ & $-2.492^{* * *}$ \\
\hline & $(0.003)$ & $(0.003)$ & $(0.002)$ & $(0.002)$ & $(0.011)$ & $(0.017)$ \\
\hline \multirow[t]{2}{*}{ No network } & $0.005^{*}$ & $-0.013^{* * *}$ & $-0.006^{* *}$ & $-0.007^{* * *}$ & -0.016 & $2.404^{* * *}$ \\
\hline & $(0.003)$ & $(0.003)$ & $(0.002)$ & $(0.002)$ & $(0.011)$ & $(0.017)$ \\
\hline \multirow[t]{2}{*}{ Rural x Adv } & $0.014^{* * *}$ & $0.013^{*}$ & $0.026^{* * *}$ & $-0.013^{* * *}$ & $0.119^{* * *}$ & 0.032 \\
\hline & $(0.005)$ & $(0.007)$ & $(0.005)$ & $(0.005)$ & $(0.028)$ & $(0.033)$ \\
\hline \multirow[t]{2}{*}{ Rural x Adv x Crop } & $-0.052^{* * *}$ & $0.023^{* * *}$ & $0.041^{* * *}$ & $-0.018^{* * *}$ & $0.068^{*}$ & -0.056 \\
\hline & $(0.007)$ & $(0.009)$ & $(0.007)$ & $(0.007)$ & $(0.039)$ & $(0.044)$ \\
\hline \multirow[t]{2}{*}{ Urb x Adv } & $0.054^{* * *}$ & $0.038^{* * *}$ & $-0.086^{* * *}$ & $0.125^{* * *}$ & $-0.772^{* * *}$ & 0.047 \\
\hline & $(0.005)$ & $(0.007)$ & $(0.005)$ & $(0.005)$ & $(0.032)$ & $(0.033)$ \\
\hline \multirow[t]{2}{*}{ Urb x Adv x Crop } & $-0.044^{* * *}$ & -0.015 & $0.016^{* *}$ & $-0.031^{* * *}$ & $0.166^{* * *}$ & $-0.166^{* * *}$ \\
\hline & $(0.007)$ & $(0.009)$ & $(0.007)$ & $(0.007)$ & $(0.049)$ & $(0.044)$ \\
\hline CIV & $-0.041^{* * *}$ & $-0.018^{* * *}$ & $-0.047^{* * *}$ & $0.029^{* * *}$ & $-0.253^{* * *}$ & $-12.661^{* * *}$ \\
\hline & $(0.002)$ & $(0.003)$ & $(0.002)$ & $(0.002)$ & $(0.013)$ & $(0.016)$ \\
\hline MLI & $-0.044^{* * *}$ & 0.002 & $-0.022^{* * *}$ & $0.024^{* * *}$ & $-0.160^{* * *}$ & $-3.253^{* * *}$ \\
\hline & $(0.002)$ & $(0.003)$ & $(0.002)$ & $(0.002)$ & $(0.011)$ & $(0.016)$ \\
\hline MRT & 0.004 & $0.051^{* * *}$ & $-0.005^{* *}$ & $0.057^{* * *}$ & $-0.188^{* * *}$ & $-4.380^{* * *}$ \\
\hline & $(0.002)$ & $(0.003)$ & $(0.002)$ & $(0.002)$ & $(0.011)$ & $(0.016)$ \\
\hline NER & $0.039^{* * *}$ & $0.188^{* * *}$ & $0.089^{* * *}$ & $0.099^{* * *}$ & 0.005 & $1.843^{* * *}$ \\
\hline & $(0.002)$ & $(0.003)$ & $(0.002)$ & $(0.002)$ & $(0.011)$ & $(0.016)$ \\
\hline SEN & $-0.027^{* * *}$ & $-0.021^{* * *}$ & $-0.035^{* * *}$ & $0.014^{* * *}$ & $-0.176^{* * *}$ & $-10.554^{* * *}$ \\
\hline & $(0.002)$ & $(0.003)$ & $(0.002)$ & $(0.002)$ & $(0.012)$ & $(0.016)$ \\
\hline Adjusted $R^{2}$ & 0.309 & 0.058 & 0.044 & 0.042 & 0.024 & 0.821 \\
\hline Country dummies & Yes & Yes & Yes & Yes & Yes & Yes \\
\hline Weights $(1 /$ s.e._$\beta)$ & No & No & No & No & Yes & No \\
\hline Observations & 308389 & 211125 & 211125 & 211125 & 211125 & 308389 \\
\hline
\end{tabular}

Notes: ${ }^{* * *},{ }^{* *},{ }^{*}$ denote significance at the 1, 5 and 10 percent confidence level respectively; standard errors in parentheses. 
Table 3: Meta-analysis on intentions to migrate internationally

\begin{tabular}{|c|c|c|c|c|c|c|}
\hline & $\beta \nexists$ & 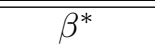 & $\overline{\beta^{*}>0}$ & $\beta^{*}<0$ & $\left|\beta^{*}\right|$ & Predict \\
\hline \multirow[t]{2}{*}{ Adverse } & $0.441^{* * *}$ & $0.120^{* * *}$ & $0.099^{* * *}$ & $0.022^{* * *}$ & $0.239^{* * *}$ & $-0.026^{* *}$ \\
\hline & $(0.002)$ & $(0.003)$ & $(0.002)$ & $(0.002)$ & $(0.012)$ & $(0.013)$ \\
\hline \multirow[t]{2}{*}{ Beneficial } & $0.266^{* * *}$ & $0.092^{* * *}$ & $0.047^{* * *}$ & $0.045^{* * *}$ & $-0.195^{* * *}$ & $-0.040^{* * *}$ \\
\hline & $(0.002)$ & $(0.003)$ & $(0.002)$ & $(0.002)$ & $(0.011)$ & $(0.013)$ \\
\hline \multirow[t]{2}{*}{ Precipitation } & $-0.161^{* * *}$ & 0.005 & $-0.070^{* * *}$ & $0.075^{* * *}$ & $-0.652^{* * *}$ & -0.032 \\
\hline & $(0.005)$ & $(0.006)$ & $(0.004)$ & $(0.004)$ & $(0.031)$ & $(0.030)$ \\
\hline \multirow[t]{2}{*}{ SPEI } & $-0.032^{* * *}$ & $0.011^{* *}$ & $-0.011^{* * *}$ & $0.021^{* * *}$ & $-0.326^{* * *}$ & $0.662^{* * *}$ \\
\hline & $(0.004)$ & $(0.005)$ & $(0.004)$ & $(0.004)$ & $(0.024)$ & $(0.023)$ \\
\hline \multirow[t]{2}{*}{ Intens. 2 sd } & $-0.174^{* * *}$ & $0.010^{* * *}$ & 0.002 & $0.008^{* * *}$ & 0.008 & $0.028^{* *}$ \\
\hline & $(0.002)$ & $(0.003)$ & $(0.002)$ & $(0.002)$ & $(0.011)$ & $(0.013)$ \\
\hline \multirow[t]{2}{*}{ Intens. 3sd } & $-0.220^{* * *}$ & $-0.008^{* * *}$ & -0.001 & $-0.007^{* * *}$ & $-0.044^{* * *}$ & $0.040^{* * *}$ \\
\hline & $(0.002)$ & $(0.002)$ & $(0.002)$ & $(0.002)$ & $(0.010)$ & $(0.013)$ \\
\hline \multirow[t]{2}{*}{ Length 12} & $0.073^{* * *}$ & $-0.010^{* * *}$ & $-0.018^{* * *}$ & $0.008^{* * *}$ & 0.004 & $0.080^{* * *}$ \\
\hline & $(0.002)$ & $(0.002)$ & $(0.002)$ & $(0.002)$ & $(0.009)$ & $(0.011)$ \\
\hline \multirow[t]{2}{*}{ Length 13-24 } & $0.020^{* * *}$ & $-0.020^{* * *}$ & $-0.011^{* * *}$ & $-0.009^{* * *}$ & 0.004 & $-0.033^{* * *}$ \\
\hline & $(0.002)$ & $(0.002)$ & $(0.002)$ & $(0.002)$ & $(0.009)$ & $(0.011)$ \\
\hline \multirow[t]{2}{*}{ Crop season } & $0.006^{* * *}$ & $-0.021^{* * *}$ & $-0.009^{* * *}$ & $-0.013^{* * *}$ & $0.031^{* * *}$ & $0.053^{* * *}$ \\
\hline & $(0.002)$ & $(0.002)$ & $(0.002)$ & $(0.002)$ & $(0.008)$ & $(0.010)$ \\
\hline \multirow[t]{2}{*}{ Rural } & $0.012^{* * *}$ & $-0.040^{* * *}$ & $-0.014^{* * *}$ & $-0.025^{* * *}$ & $0.104^{* * *}$ & $0.829^{* * *}$ \\
\hline & $(0.003)$ & $(0.004)$ & $(0.003)$ & $(0.003)$ & $(0.013)$ & $(0.019)$ \\
\hline \multirow[t]{2}{*}{ Urban } & $0.024^{* * *}$ & $0.090^{* * *}$ & $0.016^{* * *}$ & $0.074^{* * *}$ & $-0.067^{* * *}$ & $-2.055^{* * *}$ \\
\hline & $(0.003)$ & $(0.004)$ & $(0.003)$ & $(0.003)$ & $(0.014)$ & $(0.019)$ \\
\hline \multirow[t]{2}{*}{ College grads } & $0.096^{* * *}$ & $-0.031^{* * *}$ & $-0.036^{* * *}$ & $0.005^{*}$ & $0.044^{* *}$ & $2.161^{* * *}$ \\
\hline & $(0.003)$ & $(0.003)$ & $(0.003)$ & $(0.003)$ & $(0.018)$ & $(0.017)$ \\
\hline \multirow[t]{2}{*}{ Less educated } & -0.000 & 0.000 & -0.001 & 0.002 & 0.014 & -0.000 \\
\hline & $(0.003)$ & $(0.003)$ & $(0.002)$ & $(0.002)$ & $(0.012)$ & $(0.017)$ \\
\hline \multirow[t]{2}{*}{ Network } & $0.011^{* * *}$ & $-0.031^{* * *}$ & $-0.025^{* * *}$ & $-0.006^{* *}$ & $0.061^{* * *}$ & $-2.324^{* * *}$ \\
\hline & $(0.003)$ & $(0.003)$ & $(0.002)$ & $(0.002)$ & $(0.012)$ & $(0.017)$ \\
\hline \multirow[t]{2}{*}{ No network } & 0.003 & -0.002 & $-0.005^{* *}$ & 0.003 & $0.055^{* * *}$ & $2.700^{* * *}$ \\
\hline & $(0.003)$ & $(0.003)$ & $(0.002)$ & $(0.002)$ & $(0.012)$ & $(0.017)$ \\
\hline \multirow[t]{2}{*}{ Rural x Adv } & $0.016^{* * *}$ & $0.038^{* * *}$ & $0.037^{* * *}$ & 0.001 & 0.009 & 0.031 \\
\hline & $(0.005)$ & $(0.007)$ & $(0.005)$ & $(0.005)$ & $(0.029)$ & $(0.032)$ \\
\hline \multirow[t]{2}{*}{ Rural x Adv x Crop } & $-0.053^{* * *}$ & $-0.022^{* *}$ & $-0.017^{* *}$ & -0.004 & -0.064 & $-0.085^{* *}$ \\
\hline & $(0.007)$ & $(0.009)$ & $(0.007)$ & $(0.007)$ & $(0.041)$ & $(0.043)$ \\
\hline \multirow[t]{2}{*}{ Urb x Adv } & $0.057^{* * *}$ & $-0.044^{* * *}$ & $-0.067^{* * *}$ & $0.022^{* * *}$ & $-0.338^{* * *}$ & $-0.064^{* *}$ \\
\hline & $(0.005)$ & $(0.007)$ & $(0.005)$ & $(0.006)$ & $(0.034)$ & $(0.032)$ \\
\hline \multirow[t]{2}{*}{ Urb x Adv x Crop } & $-0.038^{* * *}$ & 0.011 & $0.031^{* * *}$ & $-0.020^{* * *}$ & $0.183^{* * *}$ & $0.154^{* * *}$ \\
\hline & $(0.007)$ & $(0.010)$ & $(0.008)$ & $(0.008)$ & $(0.051)$ & $(0.043)$ \\
\hline CIV & $-0.038^{* * *}$ & $0.155^{* * *}$ & $0.069^{* * *}$ & $0.085^{* * *}$ & $-0.064^{* * *}$ & $-1.751^{* * *}$ \\
\hline & $(0.002)$ & $(0.003)$ & $(0.002)$ & $(0.002)$ & $(0.013)$ & $(0.015)$ \\
\hline MLI & $-0.036^{* * *}$ & $0.109^{* * *}$ & $0.019^{* * *}$ & $0.089^{* * *}$ & $-0.330^{* * *}$ & $6.403^{* * *}$ \\
\hline & $(0.002)$ & $(0.003)$ & $(0.002)$ & $(0.002)$ & $(0.012)$ & $(0.015)$ \\
\hline MRT & 0.003 & $0.063^{* * *}$ & $0.029^{* * *}$ & $0.033^{* * *}$ & $0.049^{* * *}$ & $3.957^{* * *}$ \\
\hline & $(0.002)$ & $(0.003)$ & $(0.002)$ & $(0.002)$ & $(0.012)$ & $(0.015)$ \\
\hline NER & $0.047^{* * *}$ & $0.114^{* * *}$ & $0.062^{* * *}$ & $0.052^{* * *}$ & $0.052^{* * *}$ & $12.471^{* * *}$ \\
\hline & $(0.002)$ & $(0.003)$ & $(0.002)$ & $(0.002)$ & $(0.012)$ & $(0.016)$ \\
\hline SEN & $-0.032^{* * *}$ & $0.114^{* * *}$ & $0.034^{* * *}$ & $0.079^{* * *}$ & $-0.078^{* * *}$ & $-4.619^{* * *}$ \\
\hline & $(0.002)$ & $(0.003)$ & $(0.002)$ & $(0.002)$ & $(0.012)$ & $(0.016)$ \\
\hline Adjusted $R^{2}$ & 0.309 & 0.040 & 0.028 & 0.026 & 0.018 & 0.848 \\
\hline Country dummies & Yes & Yes & Yes & Yes & Yes & Yes \\
\hline Weights $(1 /$ s.e._$\beta)$ & No & No & No & No & Yes & No \\
\hline Observations & 307548 & 209902 & 209902 & 209902 & 209902 & 307548 \\
\hline
\end{tabular}

Notes: ${ }^{* * *},{ }^{* *},{ }^{*}$ denote significance at the 1,5 and 10 percent confidence level respectively; standard errors in parentheses. 
Overall, our meta-analysis reveals that the predictive power of the model is maximized when using SPEI shocks, when measuring shocks as the share of months with at least 2 standard deviations below the relevant long-term average value over the last 12 months, ${ }^{23}$ and during the crop-growing season (in Table 3 only), and when focusing on individuals living in rural areas. In addition, focusing on adverse shocks leads to more intuitive results $(\widehat{\beta}>0)$ and larger effects $(|\widehat{\beta}|)$. The model performs better for the less educated when focusing on the intention to move within 12 months, and better for the highly-educated when the dependent variable is represented by the dummy for intending to move to another country (last columns in Tables 2 and 3). Looking at the size of the coefficients (again, in Tables 2 and 3), the size is usually greater when using the smaller sample of highly educated respondents. However, in our preferred specifications (see Tables 4 and 5 below), the dummy for highly educated respondents does not confirm this. Restricting the sample to individuals with a family member or friend abroad (Network) drastically reduces the size of the sample and the predictive power of the model. Compared to the country of reference (i.e., Burkina Faso), the model performs better in the case of Niger, and less well for Senegal and Ivory Coast.

\section{Results}

The results of our meta-analysis are used to guide the choice of the proxy used to measure past weather shocks for region $r$ at time $t, W S_{r t}$. In our benchmark specification, we proxy $W S_{r t}$ with the share of months belonging to the local (region-specific) crop-growing season in the 12 months before the interview in which the SPEI (measured over one month) was at least 2 standard deviations below its long-term average value of zero. This entails that we are focusing on the effect of droughts on moving intentions. Hence, if $\widehat{\beta}$ is positive, this means that droughts make the origin location relatively less attractive than other intended destinations. We present below the results of our benchmark specification, and then discuss some caveats and sensitivity issues.

\subsection{Benchmark results}

Tables 4 and 5 report the results from estimating Eq. (5) using the full sample, or using the sample of low-skilled individuals from rural regions (i.e., agriculture-dependent economies where weather shocks are likely to influence crop yields). In both cases, we use as dependent variables the intention to move within 12 months (left panel) and the intention to migrate abroad (right panel). We find that moving intentions are always greater for males, always decrease with age (at least when considering individuals aged 35 and over), and usually increase with the network variable. ${ }^{24,25}$

\footnotetext{
${ }^{23}$ Or over the last 24 months when dealing with the intention to emigrate abroad, with a higher risk that many intended migrants have left (see Section 5.2).

${ }^{24}$ Notice that this applies also to the intention to move, albeit the (unspecified) destination might be internal, while this control variable relates to the existence of distance-one connections outside one's own country.

${ }^{25}$ We have also estimated a specification with self-reported household income per capita among the regressors; the inclusion of this variable entails a reduction in the sample size by 3,779 observations, as this variable is either not covered in the questionnaire (Burkina Faso in 2008) or is unavailable for a large share of the respondents (e.g., 685 out of 836 observations for Senegal in 2008). Controlling for income reduces the significance of the SPEI variable for internal migration. This appears to be mostly related to
} 
In the left panel of Table 4, where the outcome is the intention to migrate within 12 months, we obtain a positive and significant coefficient for our variable of interest for three out of six countries. A larger share of months in the crop-growing season over the previous 12 months characterized by a drought is associated with a significantly higher probability of intending to move within 12 months for Senegal, Niger, and Ivory Coast. As apparent from Figures $2 \mathrm{f}$ and $2 \mathrm{~h}$, the non-arid regions covered in Niger (the regions of Niamey, Dosso and Gaya) and Senegal are subject to large SPEI shocks. Ivory Coast is less subject to adverse weather SPEI shocks but exhibits higher intentions to move and to emigrate abroad. To the contrary, Figures $2 \mathrm{f}$ and $2 \mathrm{~h}$ show that the non-arid parts of Mauritania consist of a single region. We correctly predict moving intentions for a share of the sample comprised between 66.5 percent (Ivory Coast) and 81.0 percent (Niger).

In the right panel of Table 4 (results are amplified in Table 5) where the outcome variable is the intention to move abroad, we obtain a positive and significant coefficient for our variable of interest for one country only. A larger share of months in the cropgrowing season over the previous 12 months characterized by a drought is associated with a significantly higher probability of intending to move abroad for Niger. This is not the case in the other countries in our sample. With respect to the individual-specific controls, the effects of age, gender and network are reinforced. We correctly predict moving intentions for a share of the sample varying from 66.2 percent (Senegal) to 83.2 percent (Niger).

In general, the effect of adverse SPEI shocks are amplified in Table 5 when focusing on low-skilled respondents living in rural areas. Compared to the full sample, the SPEI coefficient increases by a factor of 1.5 to 2 for the intentions to move within 12 months; the effect on intentions to emigrate abroad becomes significant (at the $10 \%$ threshold) also in Ivory Coast. It is worth noticing that the sample selection criterion entails a drastic reduction in the sample size for Mauritania, so that standard errors for the coefficients are not produced. In general, the share of correctly predicted observations in this sample is greater than in Table 4.

the loss of statistical power due to the smaller sample size rather than to a problem of over-controlling, as results are similar when we restrict the sample without controlling for income; results are available from the Authors upon request. 


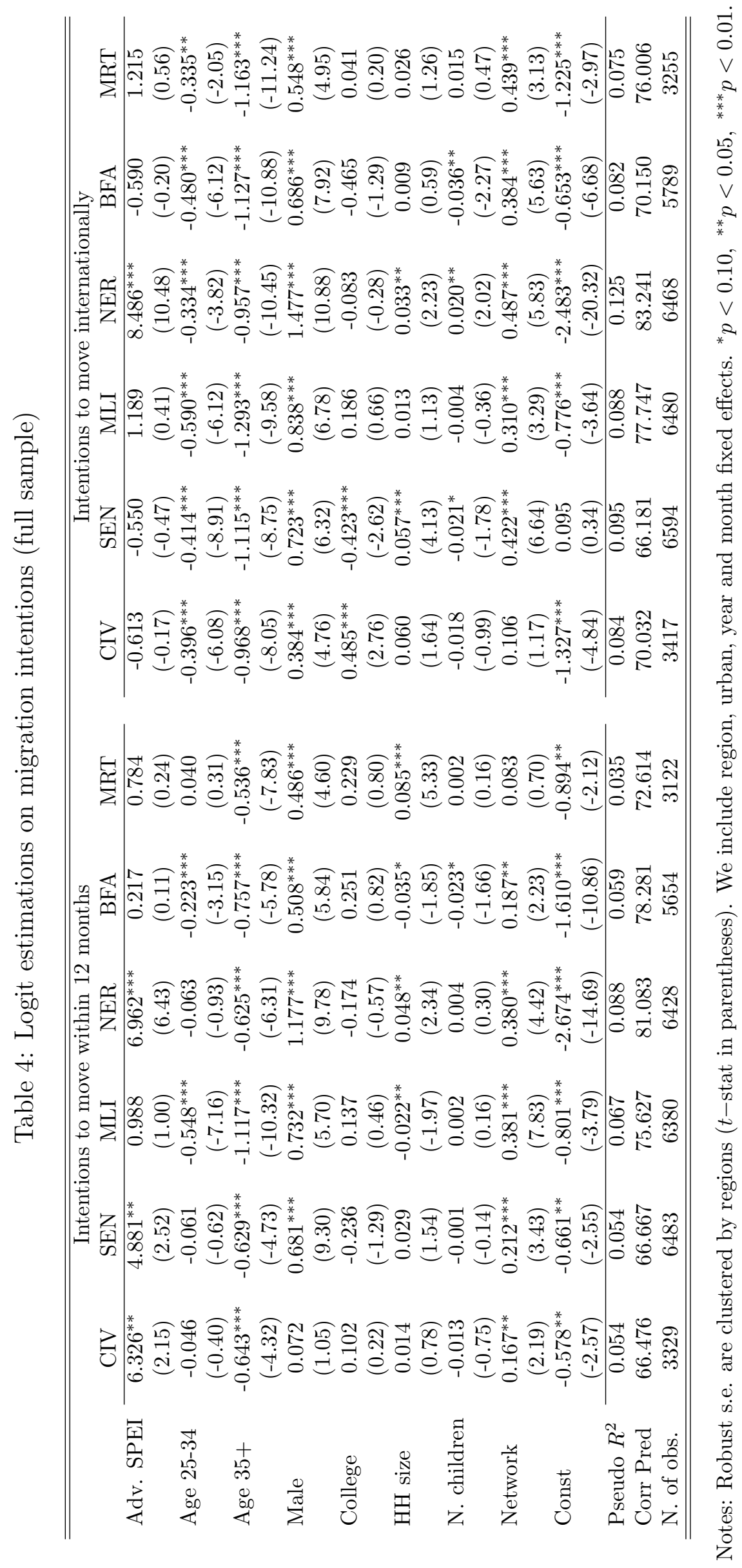




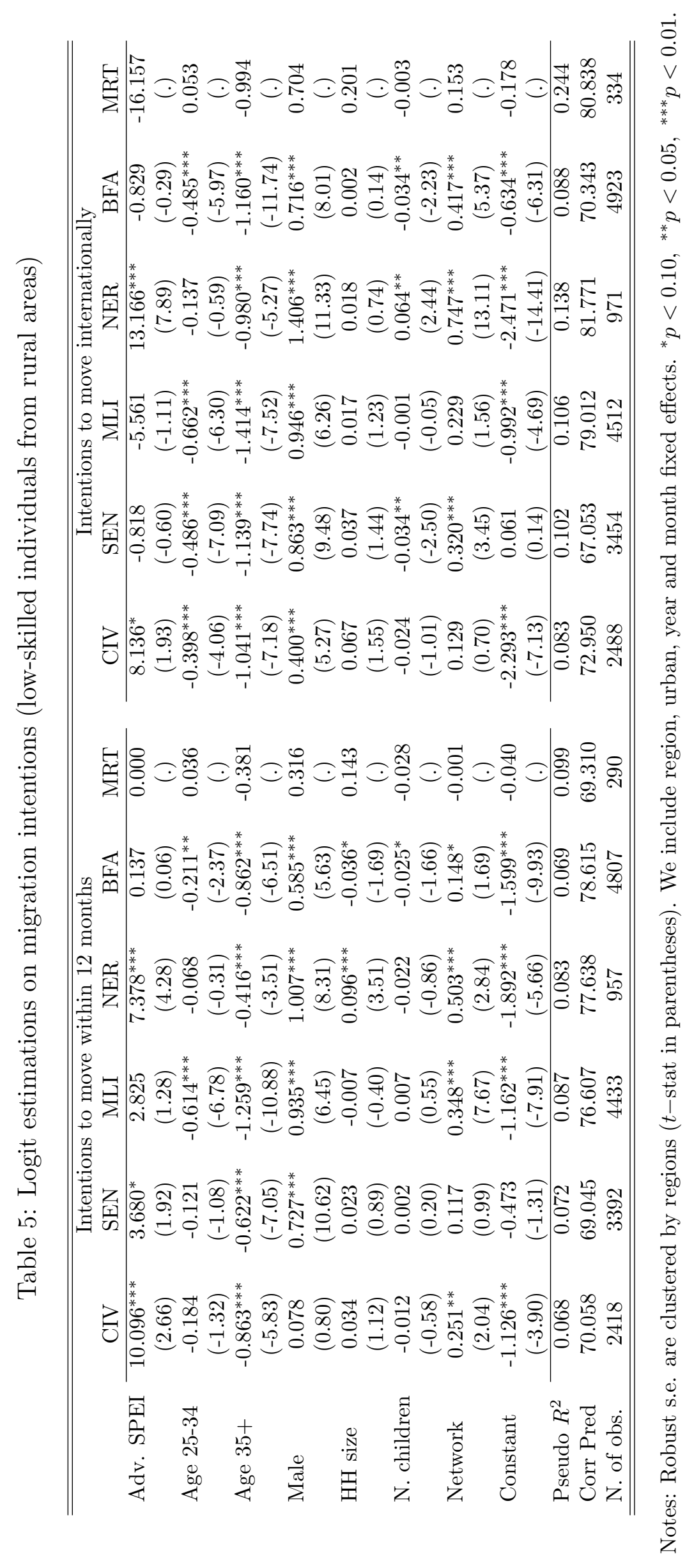




\subsection{Caveats and sensitivity}

A possible concern in the regression on the intention to move (irrespective of the destination) is the following: if an individual considers moving to a neighboring region, then weather conditions at origin could be positively correlated with weather conditions at destination, and this correlation confounds the effect of the estimated coefficient, possibly biasing it towards zero and reducing its statistical significance. Thus, when individuals have incentives to move, potential (internal) destinations may appear less attractive. This problem can be reinforced by the fact that gridded weather data are interpolated, as the data for region $r$ can actually come from ground weather stations located in neighboring regions. This, in turn, entails that the estimated coefficient for $W S_{r t}$ obtained when using $d_{i r j t}^{\text {move }}$ as our dependent variable is likely to be downward biased, so that our estimates could be interpreted as a lower bound of the true size of the effect. ${ }^{26}$

This problem might be magnified when considering smaller anomalies (e.g., one relative standard deviation from the long-term value), which are more frequent in all regions. In Tables 2 and 3, the specification with one standard deviation has a smaller predictive power than the one with 2 standard deviations for both dependent variable. Using the latter specification, our results suggest that SPEI shocks induce larger effects on intentions to move than on intentions to emigrate abroad, with the exception of Niger. We see the gap between the two coefficients (left panel minus right panel of Tables 4 and 5) as a lower bound. In Table 6 below, we show that the specification based on one standard deviation generates insignificant results (see col. 1 for shock intensity).

A further concern related to the data is that individuals might have moved between the occurrence of an extreme weather event and the date at which they are interviewed by Gallup. If individuals with the highest propensity to migrate abroad have already moved by the time of the survey, then we would be missing them entirely. ${ }^{27}$ If they moved internally (to a different region) in reaction to a negative weather shock, they might still be included in the sample, but we would be incorrectly matching them to the wrong weather conditions (the GWP do not provide information on the individual past migration history), that is, those prevailing in the region in which they moved into rather than in their region of origin, where they got exposed to a negative weather shock. A wrong association between an individual and past weather conditions introduces a measurement error in our variable of interest $W S_{r t}$; the ensuing implications for the size of the estimated coefficient are, however, ambiguous. Let us assume that internal migrants have moved to a region that has not been recently affected by a past negative weather shock; if these internal migrants intend to stay there (i.e., do not express the intention to move (again) within 12 months), then this would induce an upward bias in our estimated coefficients. But if these internal migrants have moved only on a temporary (or even seasonal) basis out of their region of origin, they might express the intention to move (return) within 12 months, thus inducing a downward bias in our estimated coefficient. Thus, the overall effect of the possible mismatch between a respondent in the GWP and past weather conditions exerts an ambiguous effect on the size (and significance) of the coefficient of our variable of interest.

\footnotetext{
${ }^{26}$ Clearly, the concern about a downward bias in the size of the estimated coefficient of interest is much less pressing when we consider intentions to migrate abroad, as the attractiveness of foreign destinations should be largely unaffected by local weather conditions.

${ }^{27}$ When estimating our logit model with $d_{i r j t}^{\text {abroad }}$ as our dependent variable, the fact that individuals whose location choices are more reactive to past local weather conditions might have disappeared from the sample would induce a downward bias in the size of our estimate for the coefficient of $W S_{r t}$.
} 
In Tables 2 and 3, it has been shown that the specification relying on 12-month shocks has the greatest predictive power. With the exception of Niger, Table 6 below shows that the effect of SPEI shocks on intentions to move becomes insignificant when extending the length of the period to 24 or 36 months (see col. 2). ${ }^{28}$

The difference in the significance of the coefficient for $W S_{r t}$ that we obtain depending on the length of the period over which we measure weather conditions is open to two alternative (but not mutually exclusive) explanations: $(i)$ individuals make their location decisions on the basis of recent (12 months) past weather conditions; when we (incorrectly) expand this period to 24 or 36 months, we are adding noise to our variable of interest, and this reduces its significance; (ii) individuals make their location decisions on the basis of weather conditions over, say, the past 36 months; if this is the case, given that consecutive waves of the GWP are, on average, only 12 months apart, we have less variability in relevant weather conditions for individuals residing in the same region, and this reduces our ability to precisely estimate the effect of our variable of interest defined over 36 months. However, notice that in this case it would be the variable measured over 12 months that would be measured with error (thus also reducing its significance), so that our results are more likely to reflect $(i)$ rather than $(i i)$, although we cannot provide conclusive arguments here.

Table 6: Logit estimations: sensitivity of $\widehat{\beta}$ to SPEI shocks (full sample)

\begin{tabular}{|c|c|c|c|c|c|c|c|}
\hline \multicolumn{2}{|c|}{ SPEI shocks } & CIV & SEN & MLI & NER & BFA & MRT \\
\hline Intens. & Length & \multicolumn{6}{|c|}{ Intentions to move within 12 months } \\
\hline $2 \mathrm{sd}$ & 12 & $6.236^{* *}$ & $4.881^{* *}$ & 0.988 & $6.962^{* * *}$ & 0.217 & 0.784 \\
\hline $1 \mathrm{sd}$ & 12 & -0.318 & 0.208 & -0.213 & -0.037 & -0.613 & -1.222 \\
\hline $2 \mathrm{sd}$ & 24 & -3.259 & 0.087 & -2.188 & $13.925^{* * *}$ & 0.912 & -0.961 \\
\hline $2 \mathrm{sd}$ & 36 & $-11.666^{*}$ & -1.262 & -0.356 & -1.047 & 2.546 & 3.728 \\
\hline Intens. & Length & \multicolumn{6}{|c|}{ Intentions to emigrate abroad } \\
\hline $2 \mathrm{sd}$ & 12 & -0.613 & -0.550 & 1.189 & $8.486^{* * *}$ & -0.590 & 1.215 \\
\hline $1 \mathrm{sd}$ & 12 & $-1.196^{*}$ & 0.073 & -0.295 & 0.477 & -0.538 & -0.130 \\
\hline $2 \mathrm{sd}$ & 24 & $-11.671^{* * *}$ & $-4.426^{*}$ & -4.726 & $16.972^{* * *}$ & -0.033 & 0.139 \\
\hline $2 \mathrm{sd}$ & 36 & $-14.985^{* * *}$ & $-5.823^{*}$ & $-10.228^{* *}$ & $14.815^{* * *}$ & -0.191 & $9.799^{* * *}$ \\
\hline
\end{tabular}

We include the same controls as before, as well as region, year and month fixed effects.

Notes: Robust s.e. are clustered by regions. ${ }^{*} p<0.10,{ }^{* *} p<0.05,{ }^{* * *} p<0.01$.

\section{Conclusion}

In this paper, we use a multilevel approach to characterize the relationship between weather shocks and (internal and international) migration intentions. Focusing on six Western African countries over the period 2008-2016, we combine individual survey data on migration intentions with various types of climate shocks measurable at a relatively detailed spatial scale. We first conduct a meta-analysis to identify the specification of weather anomalies that maximizes the goodness of fit of our empirical model. Comparing results from about 310,000 regressions, we find that the highest predictive power is obtained when defining weather anomalies as adverse SPEI shocks and when measuring shocks as the share of months with at least 2 standard deviations below the local long-term

\footnotetext{
${ }^{28}$ The effect on the intention to migrate abroad becomes negative and significant in the case of Ivory Coast, Senegal and Mali.
} 
value over the last 12 months and during the crop-growing season. Second we use this best specification to evidence heterogeneous mobility responses to weather shocks, which can be due to differences in culture or adaptation capabilities. We find that droughts are associated with a higher probability of intentions to move in Senegal, Niger, and Ivory Coast. The effect on international migration intentions are only significant in Niger, suggesting that adverse weather shocks mostly induce internal mobility responses. These effects are amplified, but qualitatively similar, when restricting the sample to low-skilled respondents from rural areas. Our results are in line with other cross-country studies (Beine and Parsons, 2015; Marchiori et al., 2012) or with studies focusing on long-term climate changes (Burzynski et al., 2019). Still, they also reveal important heterogeneous migration responses across and within countries at both the extensive and intensive margins.

\section{References}

Backhaus, A., I. Martinez-Zarzoso, And C. Muris (2015): "Do Climate Variations Explain Bilateral Migration? A Gravity Model Analysis," IZA Journal of Migration, 4.

Barrios, S., L. Bertinelli, and E. Strobl (2006): "Climatic change and ruralurban migration: The case of sub-Saharan Africa," Journal of Urban Economics, 60, $357-371$.

BAzzI, S. (2017): "Wealth Heterogeneity and the Income Elasticity of Migration," American Economic Journal: Applied Economics, 9, 219-255.

BeCERRA, D. (2012): "The Impact of anti-immigration policies and perceived discrimination in the United States on migration intentions among Mexican adolescents," International Migration, 50, 20-32.

Begueria, S., S. M. Vicente-Serrano, F. Reig, and B. Latorre (2014): "Standardized precipitation Evapotranspiration Index (SPEI) revisited: parameter fitting, evapotranspiration, tools, datasets and drought monitoring," International Journal of Climatology, 34, 3001-3023.

Beine, M. And L. Jeusette (2018): "A meta-anaysis of the literature on climate change and migration," CREA Discussion Paper Series 18-05, University of Luxembourg.

Beine, M. And C. Parsons (2015): "Climatic Factors as Determinants of International Migration," Scandinavian Journal of Economics, 117, 723-767.

Berlemann, M. and M. F. Steinhardt (2017): "Climate Change, Natural Disasters, and Migrationa Survey of the Empirical Evidence," CESifo Economic Studies, 63, 353385 .

Bertoli, S. And E. Murard (2020): "Migration and Co-Residence Choices: Evidence from Mexico," Journal of Development Economics, 142, article 102330.

Bertoli, S. And I. Ruyssen (2018): "Networks and migrants' intended destination," Journal of Economic Geography, 18, 705-728. 
Bohra-Mishra, P., M. Oppenheimer, and S. M. Hsiang (2014): "Nonlinear permanent migration response to climatic variations but minimal response to disasters," Proceedings of the National Academy of Sciences, 111, 9780-9785.

Boustan, L. P., M. E. Kahn, And P. W. Rhode (2012): "Moving to Higher Ground: Migration Response to Natural Disasters in the Early Twentieth Century," American Economic Review, 102, 238-244.

Burzynski, M., C. Deuster, F. Docquier, And J. De Melo (2019): "Climate change, inequality and human mobility," IZA DP No. 12623, Institute of Labor Economics (IZA).

Cai, R., S. Feng, M. Oppenheimer, and M. Pytlikova (2016): "Climate variability and international migration: The importance of the agricultural linkage," Journal of Environmental Economics and Management, 79, 135-151.

Cattaneo, C., M. Beine, C. J. Frhlich, D. Kniveton, I. Martinez-Zarzoso, M. Mastrorillo, K. Millock, E. Piguet, and B. Schraven (2019): "Human Migration in the Era of Climate Change," Review of Environmental Economics and Policy, 13, 189-206.

Cattaneo, C. and G. Peri (2016): "The migration response to increasing temperatures," Journal of Development Economics, 122, 127-146.

Clemens, M. A. And L. Pritchett (2016): "The New Economic Case for Migration Restrictions: An Assessment," IZA Discussion Papers 9730, Institute of Labor Economics (IZA).

Coniglio, N. D. And G. Pesce (2015): "Climate variability and international migration: an empirical analysis," Environment and Development Economics, 20, 434-468.

Dao, T. H., F. Docquier, C. Parsons, and G. Peri (2018): "Migration and development: Dissecting the anatomy of the mobility transition," Journal of Development Economics, 132, 88-101.

Dell, M., B. F. Jones, And B. A. Olken (2014): "What Do We Learn from the Weather? The New Climate-Economy Literature," Journal of Economic Literature, 52, $740-798$.

Delogu, M., F. Docquier, and J. Machado (2018): "Globalizing labor and the world economy: the role of human capital," Journal of Economic Growth, 23, 223-258.

Dillon, A., V. Mueller, And S. Salau (2011): "Migratory Responses to Agricultural Risk in Northern Nigeria," American Journal of Agricultural Economics, 93, 1048-1061.

Docquier, F., J. Machado, and K. Sekkat (2015): "Efficiency Gains from Liberalizing Labor Mobility," Scandinavian Journal of Economics, 117, 303-346.

Docquier, F., G. Peri, And I. Ruyssen (2014): "The Cross-country Determinants of Potential and Actual Migration," International Migration Review, 48, 37-99.

Docquier, F., A. TAnsel, and R. Turati (2019): "Do emigrants self-select along cultural traits? Evidence from the MENA countries," International Migration Review, doi.org/10.1177/0197918319849011. 
Drabo, A. And L. Mously Mbaye (2015): "Natural disasters, migration and education: an empirical analysis in developing countries," Environment and Development Economics, 20, 767-796.

Drinkwater, S. And P. Ingram (2009): "How Different are the British in their Willingness to Move? Evidence from International Social Survey Data," Regional Studies, 43, 287-303.

Dustmann, C. And A. Okatenko (2014): "Out-migration, wealth constraints, and the quality of local amenities," Journal of Development Economics, 110, 52-63.

EC (2015): "Mobility and Migration in West Africa," Factsheet produced for the strategic steering committee in brussels, European Commission: Brussels.

Fagan, B. (2008): The Great Warming: The Rise and Fall of Civilizations, Bloomsbury Press.

Friebel, G., M. Manchin, M. Mendola, and G. Prarolo (2018): "International Migration Intentions and Illegal Costs: Evidence Using Africa-to-Europe Smuggling Routes," CEPR Discussion Paper 13326.

Gallup (2017): Worldwide Research Methodology and Codebook, Gallup Inc: New York.

Girsberger, E. M., R. MÉango, and H. Rapoport (2019): "Regional migration and wage inequality in the West African economic and monetary union," Journal of Comparative Economics, doi.org/10.1016/j.jce.2019.10.002.

Gray, C. L. And R. Bilsborrow (2013): "Environmental Influences on Human Migration in Rural Ecuador," Demography, 50, 1217-1241.

Gray, C. L. And V. Mueller (2012a): "Drought and Population Mobility in Rural Ethiopia," World Development, 40, 134-145.

(2012b): "Natural disasters and population mobility in Bangladesh," Proceedings of the National Academy of Sciences, 109, 6000-6005.

Hamilton, E. And R. Savinar (2015): "Two Sources of Error in Data on Migration From Mexico to the United States in Mexican Household-Based Surveys," Demography, $52,1345-1355$.

Harris, I., P. Jones, T. Osborn, And D. Lister (2014): "Updated high-resolution grids of monthly climatic observations - the CRU TS3.10 Dataset," International Journal of Climatology, 34, 623-642.

Ibarraran, P. AND D. Lubotsky (2018): "Mexican immigration and self-selection: New evidence from the 2000 Mexican census," in Mexican Immigration to the United States, ed. by G. J. Borjas, University of Chigago Press, 159-192.

Iizumi, T. AND N. RamankutTy (2015): "How do weather and climate influence cropping area and intensity?" Global Food Security, 4, 46-50.

IPPC (2014): "Climate Change 2014: Synthesis Report," Geneva, switzerland, Contribution to the Fifth Assessment Report of the Intergovernmental Panel on Climate Change. 
Jalloh, A., G. C. Nelson, S. T. Thomas, R. Zougmore, and H. Roy-Macauley (2013): "West African agriculture and climate change: A comprehensive analysis," Ifpri, washington, IFPRI research monograph.

Jonsson, G. (2008): "Migration aspirations and immobility in a Malian Soninke village," IMI Working Paper 10-2008 10-2008, International Migration Institute.

Manchin, M., R. Manchin, And S. Orazbayev (2014): "Desire to Migrate Internationally and Locally and the Importance of Satisfaction with Amenities," Paper presented at the fiwwiiw seminars in international economics, 10 april 2014, austria, vienna.

Manchin, M. And S. Orazbayev (2018): "Social networks and the intention to migrate," World Development, 109, 360-374.

Marchiori, L., J.-F. Maystadt, And I. Schumacher (2012): "The impact of weather anomalies on migration in sub-Saharan Africa," Journal of Environmental Economics and Management, 63, 355-374.

(2015): "The impact of weather anomalies on migration in sub-Saharan Africa," Migration and Development, 6, 33-59.

Mastrorillo, M., R. Licker, P. Bohra-Mishra, G. Fagiolo, L. D. Estes, AND OPPENHEIMERMichaEL (2016): "The influence of climate variability on internal migration flows in South Africa," Global Environmental Change, 39, 155-169.

Mendola, M. (2018): "Global Evidence on Prospective Migrants from Developing Countries," DEMS Working Paper No. 387, Centro Studi Luca D’Agliano.

Millock, K. (2015): "Migration and Environment," Annual Review of Resource Economics, 7, 35-60.

Mueller, V., G. Clark, and K. Kosec (2014): "Heat stress increases long-term human migration in rural Pakistan," Naturel Climate Change, 1, 182-185.

New, M., M. Hulme, And P. Jones (2000): "Representing twentieth-century spacetime climate variability. Part II: Development of 1901-96 monthly grids of terrestrial surface climate," Journal of Climate, 13, 2217-2238.

Piguet, E. (2010): "Linking climate change, environmental degradation, and migration: a methodological overview," Climate Change, 1, 517-524.

Piguet, E., A. Pecoud, And P. De Guchteneire (2011): "Linking climate change, environmental degradation, and migration: a methodological overview," Refugee Survey Quarterly, 30, 1-23.

Rigaud, K., B. Jones, J. Bergmann, V. Clement, K. Ober, J. Schewe, S. Adamo, B. McCusker, S. Heuser, And A. Midgley (2018): "Groundswell: Preparing for Internal Climate Migration. Washington, DC: The World Bank," .

Ruyssen, I. And S. Salomone (2018): "Female migration: A way out of discrimination?" Journal of Development Economics, 130, 224-241. 
Thiede, B., C. Gray, and V. Mueller (2016): "Climate variability and interprovincial migration in South America, 19702011," Global Environmental Change, 41, $228-240$.

Wood, C. H., C. L. Gibson, L. Ribeiro, and P. Hamsho-Diaz (2010): "Crime Victimization in Latin America and Intentions to Migrate to the United States," International Migration Review, 44, 3-24. 